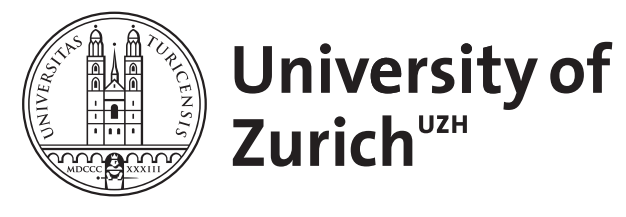

\title{
International Bond Risk Premia
}

\author{
Dahlquist, Magnus ; Hasseltoft, Henrik
}

\begin{abstract}
We identify local and global factors across international bond markets that are poorly spanned by the cross-section of yields but have strong forecasting power for future bond excess returns. Local and global factors are jointly signicant predictors of bond returns, where the global factor is closely linked to US bond risk premia and international business cycles. Motivated by our results, we estimate a noarbitrage ane term structure model for each country in which movements in risk premia are driven by one local and one global factor. Yield loadings for the two factors are estimated to be close to zero while shocks to risk premia account for a small fraction of yield variance. This suggests that the cross-section of yields conveys little information about the return-forecasting factors. We show that shocks to global risk premia cause osetting movements in expected returns and expected future short-term interest rates, leaving current yields little affected. Furthermore, correlations between international bond risk premia have increased over time, indicating an increase in integration between markets.
\end{abstract}

DOI: https://doi.org/10.1016/j.jinteco.2012.11.008

Posted at the Zurich Open Repository and Archive, University of Zurich

ZORA URL: https://doi.org/10.5167/uzh-35536

Journal Article

Originally published at:

Dahlquist, Magnus; Hasseltoft, Henrik (2013). International Bond Risk Premia. Journal of International Economics, 90(1):17-32.

DOI: https://doi.org/10.1016/j.jinteco.2012.11.008 


\title{
International Bond Risk Premia
}

\author{
Magnus Dahlquist Henrik Hasseltoft*
}

August 13, 2012

\begin{abstract}
We find evidence for time-varying risk premia across international bond markets. Local and global factors jointly predict returns. The global factor is closely linked to US bond risk premia and international business cycles. Movements in the global factor seem to drive risk premia and expected short-term interest rates in opposite directions. We consider an affine term-structure model in which risk premia are driven by one local and one global factor. Shocks to these factors account for only a small fraction of yield variance and the cross-section of yields conveys little information about the factors. Finally, correlations between international bond risk premia have increased over time, suggesting an increase in integration between markets.
\end{abstract}

Keywords: Affine model; local and global factors; time-varying risk premia. JEL Classification Numbers: E43; F31; G12; G15.

${ }^{*}$ We have benefited from discussions with: Mikhail Chernov, Peter Schotman, and Pietro Veronesi; seminar participants from the Copenhagen Business School, Stockholm School of Economics, SIFR, University of Lugano, University of St. Gallen, and Aarhus University; and participants in the European Finance Association Meeting in Frankfurt. Financial support from Bankforskningsinstitutet is gratefully acknowledged. We thank Patrick Augustin for his research assistance. Dahlquist: Stockholm School of Economics and SIFR; e-mail: magnus.dahlquist@sifr.org. Hasseltoft: University of Zurich and the Swiss Finance Institute; e-mail: henrik.hasseltoft@bf.uzh.ch. 


\section{Introduction}

It is well known that the first three principal components (PCs) of interest rates describe variations in interest rates well (e.g., Litterman and Scheinkman, 1991). However, recent evidence suggests that certain factors predict bond returns over and above the information contained in the PCs, often viewed as level, slope, and curvature factors. For example, Cochrane and Piazzesi (2005, CP) identify a factor that has strong forecasting power for US bond returns but that is not fully spanned by the first three PCs. Duffee (2011) uncovers a "hidden" factor in the US term structure that has a negligible effect on the cross-section of yields but conveys information about expected short rates and bond risk premia.

We find evidence for time-varying bond risk premia across international markets in the form of local and global factors that jointly predict returns but which are poorly spanned by the three first PCs. The local and global factors have significant forecasting power for bond returns across countries, while the classical Fama and Bliss (1987) regressions ("FB regressions") indicate weak or no evidence of predictability for countries outside the US. This stands in contrast to the existing literature (e.g., Hardouvelis, 1994, and Bekaert and Hodrick, 2001). The local factors are constructed as in Cochrane and Piazzesi (2005) for Germany, Switzerland, the UK, and the US for the period from January 1975 to December 2009. The global factor is constructed as a GDP-weighted average of the local factors and we find that it predicts bond returns with similar or higher explanatory power compared with the local factors. (Alternative ways of constructing the global factor yield similar results.)

The global factor is closely linked to US bond risk premia and international business cycles and predicts global economic growth, suggesting that it conveys important economic information. A rise in global bond risk premia is associated with a contemporaneous drop in leading economic indicators across countries but signals improved future economic conditions. Furthermore, the global factor seems to drive risk premia and expected short-term interest 
rates in opposite directions suggesting that it has a muted effect on the current level of yields. The global factor is highly correlated with US bond risk premia and predicts non-US bond returns with high $R^{2}$ s. This indicates that shocks to US risk premia are important determinants of international risk premia. We also find that correlations between local factors and the global factor have increased over time. This increase in the co-movements of international bond risk premia suggests increased integration between countries.

Supported by our results, we estimate a no-arbitrage affine term-structure model for each country in which time-varying risk premia are driven by one local and one global factor. An impulse-response analysis suggests that positive shocks to the local and global factors are associated with a drop in current and future short-term interest rates. A decomposition of the variance of yields reveals that the local and global factors only account for a small fraction of the overall variance. Furthermore, we find that risk premia are earned mainly as compensation for level shocks across all markets.

In addition to local bond returns, we consider annual returns from borrowing in USD, investing in a foreign bond, and then converting the proceeds back into USD. Returns on such a strategy reflect both local bond returns and currency returns. As with local bond returns, we find that one dominant driver of these international bond returns accounts for $80 \%$ of their variation. Based on these annual returns, we construct a global factor that predicts international bond returns with $R^{2}$ s up to $20 \%$. Our results therefore indicate significant systematic variation in expected returns for bond strategies that both include and exclude foreign exchange rate effects.

Our paper is related to a large literature on international bond markets. For example, Ilmanen (1995) examines the predictability of international bond returns and finds that global factors predict returns across countries. Our finding that bond returns are governed by local and global factors is related to Dahlquist (1995), who documents that variations in forward-term premia are largely captured by the shape of domestic and world term structures, 
and to Driessen et al. (2003), who document that a world interest rate level factor accounts for nearly half of the variation in bond returns. Perignon et al. (2007) find that US bond returns share only one common factor with German and Japanese bond returns and link this to changes in interest rates. Kessler and Scherer (2009) also consider CP factors across countries but their focus differs from ours as they are interested mainly in evaluating trading strategies. Jotikasthira et al. (2012) explore co-variation in yields across countries and find that a world inflation factor is an important driver of risk compensation for long-term bonds. However, they do not study predictability of international bond returns. ${ }^{1}$

While our focus is on international bond risk premia, several papers have focussed on US bond risk premia. For example, Ludvigson and Ng (2009) document that macro factors predict bond returns, adding incremental forecasting power in excess of information contained in yields. Cooper and Priestley (2009) find that the output gap predicts bond returns and Cieslak and Povala (2011) use long-run inflation expectations to extract a cycle factor from yields that predicts bond returns.

Moreover, the literature on no-arbitrage term-structure models is vast (see, e.g., Dai and Singleton, 2000, Duffee, 2002, and Dai and Singleton, 2002). Cochrane and Piazzesi (2008) estimate an affine model that incorporates the local CP factor and use it to analyze the term-structure of bond risk premia. Diebold et al. (2008) build on Nelson and Siegel (1987) and document global yield curve factors that appear to be linked to global macroeconomic factors such as inflation and real activity. Joslin et al. (2010) develop a term-structure model in which macro risk is unspanned by bond yields.

Furthermore, our paper is related to the literature on real and financial integration. Kose et al. (2003) focus on real integration and identify a common world factor as an important

\footnotetext{
${ }^{1}$ Also related is the literature on global factors in other asset markets. For example, Harvey (1991), Campbell and Hamao (1992), and Ferson and Harvey (1993) use global risk factors to predict international stock returns, while Backus et al. (2001) and Lustig et al. (2011) address the forward premium puzzle using affine models including country-specific and common factors.
} 
driver of macroeconomic volatility, indicating a world business cycle effect. The world factor is found to be highly correlated with US output growth, suggesting that the US economy is an important contributor to world economic fluctuations. This supports our finding that the US market is an important determinant of international risk premia. Barr and Priestley (2004) study integration of international bond markets and find that around three quarters of local risk premia are due to global risk. Several studies document significant spillover effects from US asset markets into other regions. For example, Ehrmann and Fratscher (2005) and Ehrmann et al. (2011) document large spillover effects from US financial markets onto European interest rates with the effects becoming stronger over time, arguably due to increased real integration. $^{2}$

Our finding of time-varying international bond risk premia presents a challenge for existing equilibrium models. Extensive work has been done on understanding US risk premia. Brandt and Wang (2003), Wachter (2006), and Buraschi and Jiltsov (2007) document that the habit-formation model of Campbell and Cochrane (1999) can generate time-varying bond risk premia, and Bansal and Shaliastovich (2010) and Hasseltoft (2012) document the same for the long-run risk model of Bansal and Yaron (2004). However, much less work has been done on modeling international risk premia in equilibrium, capturing economic channels across bond markets.

We proceed as follows. In Section 2 we describe the data, present summary statistics, and provide the key results related to predictability regressions of bond returns. In Section 3 we propose an affine term-structure model including local and global factors and present the results of estimating these models. In Section 4 we discuss the dynamics of the global factor and link the factor to international business cycles. We conclude in Section 5 .

\footnotetext{
${ }^{2}$ Considering other asset classes, Pukthuanthong and Roll (2009) find evidence of increased integration of international equity markets over time. Bekaert and Wang (2009) document increased integration of equity risk premia and argue it is due to globalization. Bekaert et al. (2011) find an increased convergence of country earnings yields for countries entering the European Union. For corporate bond markets, Baele et al. (2004) find evidence of increased integration over time across European countries.
} 


\section{Predictability of bond returns}

\subsection{Data}

Our dataset covers monthly zero-coupon interest rates for Germany, Switzerland, the UK, and the US and extends from January 1975 to December 2009. We use maturities of one month, three months, and one to five years for each country. One- to five-year zero-coupon yields for Germany are obtained from the Bundesbank; yields for Switzerland are derived from forward rates up to December 2003, after which yields from the Swiss National Bank are used; yields for the UK are obtained from the Bank of England; and yields for the US are collected from the Fama-Bliss discount bond file in CRSP. We also use a second set of US interest rates provided by the Federal Reserve and described in Gurkaynak et al. (2007). These rates are smoothed as opposed to the Fama-Bliss yields which are not. One- and threemonth interbank rates, obtained from Datastream, are used for Germany, Switzerland, and the UK. The Fama one- and three-month Treasury yields from CRSP are used for the US. ${ }^{3}$

Monthly data on exchange rates are obtained from Datastream. Quarterly GDP data for each country, computed using purchasing power parity, are obtained from OECD. As the GDP data are quarterly, the weights applied to the monthly CP factors are constant in each quarter. We also consider data from OECD in the form of leading economic indicators and industrial production and data from the Survey of Professional Forecasters in the form of quarterly observations of expected future short-term interest rates for the US.

Table 1 presents summary statistics for yields across countries. Yield curves tend to be upward sloping on average, while yields on short-maturity bonds tend to be more volatile than yields on long-maturity bonds. Yields are positively correlated across countries, cor-

\footnotetext{
${ }^{3}$ Fontaine and Garcia (2012) demonstrate that short-term interbank and government rates exhibit different dynamics, particularly during periods of funding stress. Though this could affect our results, we think it has a marginal impact because we use only short rates when estimating the affine term-structure models to tie down the short end of the yield curves. One- and three-month rates are not used in any of the predictability regressions.
} 
relations being higher among yields on longer-term bonds. Annual bond excess returns on two- to five-year bonds are also positively correlated across countries, as indicated in Table 2.

\subsection{Constructing local and global Cochrane-Piazzesi factors}

We construct local CP factors as in Cochrane and Piazzesi (2005) for each country, c, in our sample. The annual return on an $n$-period bond in excess of the one-year yield is defined as $r x_{c, t+12}^{n}=p_{c, t+12}^{n-1}-p_{c, t}^{n}-y_{c, t}^{1}$, where $p$ denotes the log bond price and $y$ denotes the $\log$ yield, computed as $y_{c, t}^{n}=-p_{c, t}^{n} / n$. We measure the maturity, $n$, in years and the time, $t$, in months, and define the one-year forward rate between periods $n-1$ and $n$ as the differential in $\log$ bond prices, i.e., $f_{c, t}^{n}=p_{c, t}^{n-1}-p_{c, t}^{n}$. A CP factor is constructed by regressing average excess returns across maturity at each time $t$ on the one-year yield and four forward rates:

$$
\overline{r x}_{c, t+12}=\gamma_{c, 0}+\gamma_{c, 1} y_{c, t}^{1}+\gamma_{c, 2} f_{c, t}^{2}+\gamma_{c, 3} f_{c, t}^{3}+\gamma_{c, 4} f_{c, t}^{4}+\gamma_{c, 5} f_{c, t}^{5}+\bar{\epsilon}_{c, t+12},
$$

where $\overline{r x}_{c, t+12}=\sum_{n=2}^{5} r x_{c, t+12}^{n} / 4$. Let the right-hand-side variables, including the constant term, for each country be collected in vector $f_{c, t}$ and let the corresponding estimated coefficients be collected in vector $\hat{\gamma}_{c}$. A local CP factor, $C P_{c, t}$, is then given by $\hat{\gamma}_{c}^{\prime} f_{c, t} \cdot{ }^{4}$ The CP factors as of date $t$ are later used to predict future excess returns. Note that the factors are constructed based on information for the entire sample (i.e., using information beyond date t). We have US data for a longer sample starting in 1953 and consider a recursive estimation of the US factor (i.e., the factor as of date $t$ is constructed based solely on information up

\footnotetext{
${ }^{4}$ Cochrane and Piazzesi (2005) find that the $\gamma$ s are tent-shaped. We find a similar pattern for the US, using the same data source as CP but for a different sample period. The patterns are different for the remaining countries. Dai et al. (2004) emphasize that different ways of smoothing yield curves give rise to different patterns. Yields that are choppy and less smoothed produce patterns that are more tent shaped. While the US yields we use are unsmoothed Fama-Bliss yields, yields for the remaining countries are smoothed by each country's central bank, so the patterns differ. However, including only the one-year yield, the three-year forward rate, and the five-year forward rate on the right-hand side produces tent shapes for smoothed yields as well, without substantially changing the dynamics of the $\mathrm{CP}$ factor.
} 
to that time). The full sample factor and the recursive factor are remarkably similar with a correlation of 0.85 . We lack longer data histories for the other countries and therefore do not consider recursive constructions of factors.

We construct a global factor defined as the GDP-weighted average of each local CP factor at time $t$ :

$$
G C P_{t}=\sum_{c=1}^{C} w_{c, t} C P_{c, t},
$$

where $w_{c, t}=G D P_{c, t} / \sum_{c=1}^{C} G D P_{c, t}$ and $C=4$. The average weights over the sample period are 0.17 for Germany, 0.02 for Switzerland, 0.11 for the UK, and 0.70 for the US. Our GDP-weighted global risk factor is hence dominated by the US. ${ }^{5}$

Table 3 presents correlations of the local CP factors as well as the global factor. While the US factor is only weakly positively correlated with the others, the European factors display higher correlations among each other. Correlations are higher in the second half of the sample period, in which correlations exceed 0.5. This suggests that international bond risk premia have become more correlated over time. This can also be seen in Figure 1, which depicts the four local CP factors together with peak-to-trough contractions as dated by the NBER for the US and by the Economic Cycle Research Institute for the other countries. The table also shows that the US factor and the global factor are almost perfectly correlated, while correlations are lower than 0.5 for the other countries. Figure 2 depicts the global factor together with US contractions. The global factor tends to increase during US recessions, indicating that it is closely related to US economic conditions. We discuss this further in Section 4 .

\footnotetext{
${ }^{5}$ We have considered alternative ways of constructing a global factor; for example, we have tried out an equal-weighted factor and a factor given by the first PC of the covariance matrix of local CP factors. Our main result, that bond risk premia are determined by both a local and a global factor, remains.
} 


\subsection{Predictability regressions}

We start by running FB regressions for each country. We regress annual excess returns on an $n$-period bond onto a constant and the forward rate-spot rate differential:

$$
r x_{c, t+12}^{n}=a_{c}^{n}+b_{c}^{n}\left(f_{c, t}^{n}-y_{c, t}^{1}\right)+\epsilon_{c, t+12}^{n},
$$

where $a_{c}^{n}$ and $b_{c}^{n}$ are parameters and $\epsilon_{c, t+12}^{n}$ is an error term. Table 4 presents the results. Consistent with earlier evidence in the literature, we find that a positive forward-spot rate spread positively predicts US returns, with $R^{2}$ s ranging between $4 \%$ and $11 \%$. Slope coefficients for maturities of two to four years are statistically significant at the $1 \%$ level, while the coefficient for the five-year bond is statistically significant at the $10 \%$ level. However, none of the predictability coefficients for the UK and Germany are statistically different from zero at conventional significance levels, while for Switzerland, slope coefficients for the twoand three-year bonds are significant. The predictive power of the regressions is considerably lower for Germany and the UK relative to the US. The findings are in line with existing evidence that it is more difficult to reject constant risk premia for countries outside the US. The $90 \%$ confidence intervals for the $R^{2}$ s highlight the general uncertainty in the predictive power. ${ }^{6}$

Next, we predict bond returns using our constructed local CP factors and run the following regression for each country:

$$
r x_{c, t+12}^{n}=a_{c}^{n}+b_{c, C P}^{n} C P_{c, t}+\epsilon_{c, t+12}^{n} .
$$

\footnotetext{
${ }^{6}$ The confidence intervals for the $R^{2} \mathrm{~s}$ are based on a block bootstrap simulation with 1,000 repetitions. We follow Politis and White (2004) and Politis, White, and Patton (2009) and generate optimal block sizes for the stationary block bootstrap method of Politis and Romano (1994), maintaining serial correlation and conditional heteroskedasticity in the data. We have considered alternative bootstrap methods and the confidence intervals do not seem to be sensitive to the chosen method.
} 
Table 4 presents these results as well. Predictability coefficients are all highly significant across the four countries and the explanatory power of the regressions is at least twice the $R^{2}$ s found in the FB regressions. For countries in which the FB regressions provide weak or no evidence of predictability, the CP regressions suggest that international bond risk premia are indeed predictable. This is likely because CP regressions use more information from the yield curve than do the FB regressions. The greater predictability in the CP regressions can also be seen in the $90 \%$ confidence intervals for the $R^{2}$ s. For all countries the intervals do not include a zero $R^{2}$.

To put the explanatory power of the local CP factors in greater context, we contrast the results to those obtained using the first three PCs of yield levels to predict returns. It is common in the term-structure literature to summarize the information in yields using these components, as they explain virtually all of the variation in yields (see, e.g., Litterman and Scheinkman (1991)). The first three components are often labeled level, slope, and curvature. We conduct a PC analysis of yield levels for each country ${ }^{7}$ and then run the following regression for each country:

$$
r x_{c, t+12}^{n}=a_{c}^{n}+b_{c, \text { Level }}^{n} \text { Level }_{c, t}+b_{c, \text { Slope }}^{n} \text { Slope }_{c, t}+b_{c, \text { Curvature }}^{n} \text { Curvature } e_{c, t}+\epsilon_{c, t+12}^{n} .
$$

The results of these regressions are presented in Table 5. Judging from the statistical significance of the coefficients, the slope factors seem important for predicting returns. Furthermore, the explanatory power is higher than for the FB regressions for all countries. However, the $R^{2}$ s are lower than when using the local CP factors, except for Switzerland, in which case the explanatory powers of the two regressions are similar. We also run a "horse race" between local CP factors and PCs by including them jointly as predictive variables. The

\footnotetext{
${ }^{7}$ The $\mathrm{PC}$ analysis is conducted using an eigenvalue decomposition of the variance-covariance matrix of demeaned yield levels. As in the literature, we find that the first three PCs account for virtually all variation in yields.
} 
results of this are reported in the online Appendix and indicate that the local $\mathrm{CP}$ factors enter as highly significant and drive out the significance of the local slope factors. ${ }^{8}$

To sum up the results so far, the local CP factors all predict bond returns with a significantly higher $R^{2}$ than do the commonly used FB regressions, and they seem to convey more information than do the first three PCs, with the possible exception of the case of Switzerland.

Based on our earlier discussion of international bond risk premia being positively correlated, we investigate whether a common global factor predicts returns for each country. Using our constructed global factor, we predict excess returns by running the following regression:

$$
r x_{c, t+12}^{n}=a_{c}^{n}+b_{c, G C P}^{n} G C P_{t}+\epsilon_{c, t+12}^{n} .
$$

Table 6 presents the results. Interestingly, the $R^{2}$ s are about the same or higher for the European countries compared with using the local CP factors. As the global factor is highly correlated with the US factor, our results suggest that shocks to US bond risk premia have great predictive power for bond returns outside the US. Similar $R^{2} \mathrm{~s}$ for the US indicate that incorporating information from other countries is less important for predicting US bond returns. ${ }^{9}$

Having established that both local and global CP factors significantly predict returns with high $R^{2}$, we include the local and global factors jointly and run the following regression:

$$
r x_{c, t+12}^{n}=a_{c}^{n}+b_{c, C P}^{n} C P_{c, t}+b_{c, G C P}^{n} G C P_{t}+\epsilon_{c, t+12}^{n} .
$$

\footnotetext{
${ }^{8}$ Our main regression specifications use the level of yields to compute PCs. For robustness, we also predict returns using PCs based on yield changes; the results of this are reported in the online Appendix. We find that the overall level of predictability is similar to that of our main specification, but that it is the first component, i.e., yield changes, that enters as highly significant rather than the second component.

${ }^{9}$ Running the predictability regression using the US factor confirms the importance of US risk premia for predicting international bond risk premia.
} 
To simplify the interpretation of the results, we first orthogonalize the local factors with respect to the global factor. More specifically, we regress the local factors onto the global factor and treat the residuals as the truly local factors; these results are also presented in Table 6. For the US, the global factor has little extra forecasting power and the local slope coefficients are insignificant. For the other countries, both local and global slope coefficients are individually and jointly significant. The $R^{2}$ are also higher than in the individual regressions. Note that the lower bounds on the $90 \%$ confidence intervals are higher in these joint regressions than in previous regressions. The joint significance of the coefficients suggests that bond risk premia are driven by both local and global factors. We plot the time-varying risk premia for each country, stemming from equation (7), in the online Appendix.

We also run the above regressions using smoothed US interest rates provided by the Federal Reserve and discussed in Gurkaynak et al. (2007); we report these results in the online Appendix. We find that using these rates implies a somewhat lower predictive power than does using the Fama-Bliss rates. This indicates that the predictability of CP factors depends partly on the yield construction method. Notably, however, the overall level of predictability of local and global factors is still high when using smoothed US rates and significantly higher than that obtained from the classical FB regressions.

For robustness, we also run predictive regressions using two additional datasets that extend the number of countries and cover different sample periods. ${ }^{10}$ These regressions can be viewed as an out-of-sample test of the ability of local and global factors to predict returns. The results of these regressions support our main findings that bond risk premia are driven by both local and global factors and that these factors have considerably higher forecasting power compared with the classical FB regressions.

\footnotetext{
${ }^{10}$ The first dataset covers 10 countries and is provided by Jonathan Wright and used in Wright (2011), while the second dataset covers 19 countries and consists of Citigroup world government bond total return indices in local currencies, available from Datastream.
} 
Having demonstrated that the GCP factor has considerable forecasting power for local bond returns, a natural question is whether this carries over to an international bond strategy that involves foreign exchange rate movements. We are particularly interested in the excess return for a US investor who borrows for one year in USD, invests in a foreign government bond in Germany, Switzerland, or the UK with maturities of two to five years, and then converts the proceeds back into USD after one year.

The return on this strategy can be written as $r x_{F X, t+12}^{n}=\Delta s_{i, t+12}+r_{c, t+12}^{n}-y_{U S, t}^{1}$ for currency pairs $s_{i}=\mathrm{EUR} / \mathrm{USD}, \mathrm{CHF} / \mathrm{USD}$, and GBP/USD and where $r_{c, t+12}^{n}=p_{c, t+12}^{n-1}-p_{c, t}^{n}$. The left columns of Table 7 present the results of regressing these returns onto the GCP factor. Virtually all the predictability is lost for the UK, while returns on longer maturity bonds in Germany and Switzerland do display predictability, yielding $R^{2} \mathrm{~s}$ in the range of 4-10\% with significant slope coefficients.

We can decompose the overall return, $r x_{F X, t+12}^{n}=\Delta s_{i, t+12}+r_{c, t+12}^{n}-y_{U S, t}^{1}$, into two parts by adding and subtracting the local short rate, $y_{c, t}^{1}$. The first part equals the one-year foreign exchange (FX) excess return, $\Delta s_{i, t+12}+y_{c, t}^{1}-y_{U S, t}^{1}$, and the second part equals the one-year local bond excess return, $r_{c, t+12}^{n}-y_{c, t}^{1}$. This implies that the slope coefficients from regressing FX excess returns and local bond excess returns on $G C P$ should sum up to the slope coefficients from the overall international bond return regression. The online Appendix presents the results of these complementary regressions. We find that the global factor has only weak predictive power for future annual FX excess returns but has considerable forecasting power for local bonds. The differences in predictability can also be inferred from the $90 \%$ confidence intervals for the $R^{2}$ s. Hence, the results suggest that, while GCP has some predictive power for returns on the international bond strategy, the forecasting power seems to come almost exclusively from its ability to predict local bond excess returns. Including FX returns seems to add mostly noise.

The weaker predictability from predicting international rather than local bond returns is 
perhaps not surprising, as the GCP factor is constructed using local bond returns, ignoring any foreign exchange rate effects. To further examine any potential systematic variation in expected returns of the international bond strategy, we consider a new variable called FXGCP. This variable is constructed as the fitted value from a regression of the average excess returns, $\overline{r x}_{F X, t+12}$, across all currency pairs and bond maturities at time $t+12$ onto the same set of five interest rates at time $t$ used to construct the standard CP factor.

We find that the FXGCP factor has a correlation of 0.50 with GCP across the sample period, indicating that foreign exchange rates have a sizeable impact on the FXGCP factor. Conducting a PC analysis of $r x_{F X, t+12}$ reveals a dominant factor that explains $80 \%$ of the variation in returns. Hence, as with local bond returns, there is one dominant driver of bond returns that incorporates foreign exchange rates. The right columns of Table 7 show that the FXGCP factor recovers much of the predictability that was lost earlier. While the

$R^{2} \mathrm{~s}$ for the UK are in the range of $4-6 \%$ with mostly significant coefficients, returns from investing in Germany and Switzerland display significant predictability with $R^{2}$ s reaching $20 \%$ for five-year bonds and all slope coefficients being highly significant. It is interesting to compare these results with those in Table 6 , in which local bond excess returns were projected onto CP and GCP. Unlike in the UK case, the evidence of predictability for Germany and Switzerland is similar across the various specifications.

\section{An affine model with local and global factors}

Encouraged by our finding that international bond risk premia seem to be driven by a common global factor as well as country-specific factors, in this section we explore how the return-forecasting factors drive risk premia. We are interested in discovering how shocks to the factors affect yields and risk premia and whether this differs across countries. We do so by estimating a standard Gaussian affine no-arbitrage term-structure model for each 
country.

The model consists of five factors for Germany, Switzerland, and the UK: the local CP factor, the global CP factor, and the first three PCs of yields. We orthogonalize the local $\mathrm{CP}$ factors with respect to the global CP factor through a standard OLS regression treating the residuals as the truly local factors. As the US factor and the global factor are nearly perfectly correlated, we choose to estimate a four-factor model for the US consisting of the global factor and the first three PCs. ${ }^{11}$ Consistent with the results of the predictive regressions, we assume that risk premia are driven solely by the local and global CP factors. The PCs are needed to explain the cross-section of yields but they do not drive risk premia in the model. ${ }^{12}$

As our focus is on bond risk premia, we abstract from foreign exchange in our affine model. Modeling currency risk premia jointly with local bond risk premia using our constructed factors is an interesting avenue of research that we leave for future work.

\subsection{Setup of the model}

The model is described for one country using $K$ state variables and is formulated on a monthly frequency. For simplicity, we suppress the country subscript, c. Assume that the vector of state variables follows:

$$
X_{t}=\mu+\rho X_{t-1}+\eta_{t}
$$

where $\eta_{t} \sim N(0, \Sigma)$, and $X, \mu$, and $\eta$ are $K \times 1$ vectors, and $\rho$ and $\Sigma$ are $K \times K$ matrices. The state vector contains $C P_{c, t}, G C P_{t}$, Level $_{c, t}, S_{\text {lope }}, t$, and Curvature $_{c, t}$ for Germany,

\footnotetext{
${ }^{11}$ It makes little difference to the results whether we instead use the local US factor. Furthermore, it makes little difference whether we use smoothed US rates instead of Fama-Bliss rates when estimating the models.

${ }^{12}$ Our state variables have the benefit of being observable as opposed to latent. However, the model includes circularity as the state variables, driving yields, are themselves based on these yields. Imposing restrictions on the model to account for this is complex, especially since the global factor is constructed from yields across countries. We therefore abstract from this when estimating our models.
} 
Switzerland, and the UK, and $G C P_{c, t}$, Level $_{c, t}$, Slope $_{c, t}$, and Curvature $e_{c, t}$ for the US.

The discount factor is specified as an exponentially affine function of the state variables:

$$
M_{t+1}=\exp \left(-\delta_{0}-\delta_{1}^{\prime} X_{t}-\lambda_{t}^{\prime} \eta_{t+1}-\frac{1}{2} \lambda_{t}^{\prime} \Sigma \lambda_{t}\right),
$$

where $\lambda_{t}$ is the time-varying market price of risk. The process for $\lambda_{t}$ is assumed to be affine: $\lambda_{t}=\lambda_{0}+\lambda_{1} X_{t}$, where $\lambda_{0}$ is a $K \times 1$ vector and $\lambda_{1}$ is a $K \times K$ matrix. The price of an asset satisfies standard no-arbitrage conditions, such that bond prices can be computed from $P_{t}^{n+1}=E_{t}\left(M_{t+1} P_{t+1}^{n}\right)$. Bond prices then become exponential affine functions of the state variables $P_{t}^{n}=\exp \left(A_{n}+B_{n}^{\prime} X_{t}\right)$, where $A_{n}$ is a scalar and $B_{n}$ is a $K \times 1$ vector. The $A$ s and Bs satisfy:

$$
\begin{aligned}
& A_{n+1}=A_{n}+B_{n}^{\prime} \mu^{*}+\frac{1}{2} B_{n}^{\prime} \Sigma B_{n}-\delta_{0}, \\
& B_{n+1}=\rho^{*^{\prime}} B_{n}-\delta_{1},
\end{aligned}
$$

where $A_{0}=B_{0}=0 . \mu^{*}=\mu-\Sigma \lambda_{0}$ and $\rho^{*}=\rho-\Sigma \lambda_{1}$ are the mean vector and transition matrix under the risk-neutral measure. The continuously compounded yield, $y_{t}^{n}$, is given by: $y_{t}^{n}=-\ln \left(P_{t}^{n}\right) / n=-A_{n} / n-B_{n}^{\prime} X_{t} / n$. This implies that the one-month yield follows:

$$
r_{t}=\delta_{0}+\delta_{1}^{\prime} X_{t}
$$

where $\delta_{0}$ is a scalar and $\delta_{1}$ is a $K \times 1$ vector. Model yields are subject to constant second moments as the state vector is assumed to be homoscedastic. This is obviously counterfactual to data but simplifies the analysis. 


\subsection{Risk premia and market prices of risk}

The expected one-period (one-month) log excess return on an $n$-period bond over the short rate is given by:

$$
E_{t}\left(r x_{t+1}^{n}\right)=-\operatorname{Cov}_{t}\left(m_{t+1}, r x_{t+1}^{n}\right)-\frac{1}{2} \operatorname{Var}_{t}\left(r x_{t+1}^{n}\right),
$$

where $r x_{t+1}^{n}=p_{t+1}^{n-1}-p_{t}^{n}-y_{t}^{1}$ denotes the log excess return, $p$ denotes the log bond price, $m$ denotes the log discount factor, and the variance term is a Jensen's inequality term. Recognizing that the covariance term can be written as

$$
\begin{aligned}
-\operatorname{Cov}_{t}\left(m_{t+1}, r x_{t+1}^{n}\right) & =\operatorname{Cov}_{t}\left(\eta_{t+1}, r x_{t+1}^{n}\right) \lambda_{t} \\
& =B_{n-1}^{\prime} \Sigma \lambda_{t}
\end{aligned}
$$

and that the variance term can be written as

$$
\frac{1}{2} \operatorname{Var}_{t}\left(r x_{t+1}^{n}\right)=\frac{1}{2} B_{n-1}^{\prime} \Sigma B_{n-1},
$$

the log excess return can then be written as

$$
E_{t}\left(r x_{t+1}^{n}\right)=B_{n-1}^{\prime} \Sigma \lambda_{0}+B_{n-1}^{\prime} \Sigma \lambda_{1} X_{t}-\frac{1}{2} B_{n-1}^{\prime} \Sigma B_{n-1} .
$$

Risk premia vary over time due to the time-varying market price of risk, $\lambda_{t}$, rather than due to time-varying volatility of the state vector, and equal zero when $\lambda_{0}=0$ and $\lambda_{1}=0$, ignoring the Jensen's inequality term. Equation (16) demonstrates that $\lambda_{1}$ governs the price of the market risk that is time varying. The sign of the time-varying part of the risk premium depends on the sign of the market price of the risk and on the product of yield loadings and the variance-covariance matrix $B_{n-1}^{\prime} \Sigma$. The usual intuition holds: the risk premium is positive if shocks to the state variables induce a negative covariance between the pricing 
kernel and excess returns, as this implies low excess returns in bad times.

Based on our finding that risk premia are driven by a local and a global factor, we would like to restrict the market prices of risk such that only these two factors drive risk premia in each country. In addition, we restrict the type of shocks that affect risk premia. We find that shocks to the level factor co-vary considerably and negatively with shocks to bond returns across all four countries. The covariance between return shocks and shocks to the other state variables are much smaller in magnitude. This suggests that level shocks are the most economically relevant source of risk premia across international bond markets. This is consistent with the findings of Cochrane and Piazzesi (2008) for the US. The online Appendix reports covariances and correlations between return shocks and shocks to the state variables.

Based on this, we restrict market prices of risk such that only level shocks are priced. We can impose these restrictions by setting the columns of $\lambda_{1}$ in equation (16) that refer to the level, slope, and curvature factors to zero and all rows pertaining to non-level shocks to zero. These restrictions translate into the following $\lambda_{1}$ matrix for countries outside the US:

$$
\lambda_{1}=\left(\begin{array}{ccccc}
0 & 0 & 0 & 0 & 0 \\
0 & 0 & 0 & 0 & 0 \\
\lambda_{11} & \lambda_{12} & 0 & 0 & 0 \\
0 & 0 & 0 & 0 & 0 \\
0 & 0 & 0 & 0 & 0
\end{array}\right),
$$

while the corresponding matrix for the US is:

$$
\lambda_{1}=\left(\begin{array}{cccc}
0 & 0 & 0 & 0 \\
\lambda_{11} & 0 & 0 & 0 \\
0 & 0 & 0 & 0 \\
0 & 0 & 0 & 0
\end{array}\right),
$$


as only the global factor is assumed to drive risk premia in the US market. We also impose restrictions on $\lambda_{0}$ such that only level shocks matter, in order to be consistent.

\subsection{Estimation}

In a first step, we estimate the risk-neutral dynamics of the state variables directly from observed yields. We then estimate the market prices of risk in $\lambda_{1}$ in a second step such that the model matches the slope coefficients of the in-sample predictability regressions that jointly include the local and global CP factors. ${ }^{13}$

The risk-neutral dynamics of the state variables are estimated by matching model-implied yields to observed yields. All state variables are demeaned before estimation (i.e., $\mu$ equals zero). We use an estimate of $\Sigma$ from an OLS estimation of the state dynamics in equation (8). We estimate $\lambda_{0}, \rho^{*}, \delta_{0}$, and $\delta_{1}$ by minimizing the mean-squared errors between model yields and actual yields:

$$
\frac{1}{N} \sum_{n=1}^{N} \frac{1}{T} \sum_{t=1}^{T}\left(y_{t}^{n, \text { model }}-y_{t}^{n, \text { data }}\right)^{2},
$$

where $N$ is the total number of bonds considered (here, seven) and $T$ is the number of observations in the time series. In total, 32 parameters are estimated for countries outside the US, consisting of $\delta_{0}$, the five elements of $\delta_{1}$, the one element of $\lambda_{0}$, and the 25 elements of $\rho^{*}$. For the US, a total of 22 parameters must be estimated. The risk-neutral dynamics of the state variables are restricted to being stationary throughout the estimations.

Based on our regressions, expected annual excess returns can be written as $E_{t}\left(r x_{c, t+12}^{n}\right)=$ $a^{n}+b_{c, C P}^{n} C P_{c, t}+b_{c, G C P}^{n} G C P_{t}$ for $n=2,3,4,5$ for countries outside the US and with only the GCP factor on the right-hand side for the US case. We now want to match the estimated regression coefficients from Section 2 to the model-implied slope coefficients in equation (16).

\footnotetext{
${ }^{13}$ A similar estimation strategy is used by, for example, Cochrane and Piazzesi (2008) and Koijen et al. (2012). We find this two-step estimation convenient as it achieves low pricing errors while allowing for restricted market prices of risk.
} 
We have estimated the loadings, $B$, the risk-neutral transition matrix, $\rho^{*}$, the variancecovariance matrix, $\Sigma$, and $\lambda_{0}$ from the first step, so the only unknown parameters are the $\lambda_{1}$ parameters. We estimate the market prices of risk in $\lambda_{1}$ by matching the empirical slope coefficients expressed on a monthly basis. This is done by minimizing the squared difference between model-implied and estimated regression coefficients. This entails matching eight regression coefficients to two parameters in $\lambda_{1}$ for countries outside the US, and matching four slope coefficients to one parameter for the US. ${ }^{14}$

\subsection{Results}

The pricing errors of the estimated model, as measured by the root-mean-squared error of yield in \% per year, are 0.07 for Germany, 0.10 for Switzerland, 0.16 for the UK, and 0.16 for the US. The variation in pricing errors tends to be highest for short-maturity bonds, which are known to be more difficult to model. The details and further yield diagnostics are reported in the online Appendix.

We compute yield loadings from estimated risk-neutral dynamics; these are depicted in Figure 3. The level, slope, and curvature factors take their usual shapes, well documented by others. More interestingly, loadings for the local and global return-forecasting factors are all near zero, which implies that the cross-section of yields as of date $t$ conveys very little information about the two factors. This is despite them being strong predictors of future returns. A regression of the global factor on the first three PCs of local yields supports the notion that global risk premia are poorly spanned by yields. The $R^{2} \mathrm{~s}$ in these un-tabulated regressions are $64 \%, 20 \%, 22 \%$, and $29 \%$ for the four countries. This indicates that risk premia and local term structures are somewhat related, though much of the variation in global risk premia remains unspanned by local yields.

\footnotetext{
${ }^{14}$ Our main focus is on matching movements in conditional expected returns, so we do not re-estimate $\lambda_{0}$ in the second stage. However, the model-implied regression constants are near the empirical ones.
} 
Next, we conduct an impulse-response analysis to understand how shocks to risk premia affect yields. Figure 4 and 5 depict impulse-response functions for yields on one-month and five-year bonds, given a one-standard-deviation shock to the state variables. The figure shows that a rise in risk premia is associated with a drop in current and future short-term interest rates. For example, a shock to the global factor initially lower US short rates by approximately 20 basis points over the first year, after which they gradually revert. A similar effect is found for the other countries. In contrast, shocks to risk premia tend to increase long-term rates across all countries. However, the effect of shocks to risk premia on yields is generally much smaller than that of shocks to the PCs. Overall, positive shocks to risk premia lower short rates and raise long-term rates, steepening the yield curve. This is consistent with the notion that yield curves steepen in bad times when risk premia increase.

The impulse-response analysis indicates that shocks to bond risk premia are not very persistent, being much less persistent than are, for example, movements in business cycles. This would be in contrast to economic models suggesting that risk premia move countercyclically relative to business cycles. However, there seems to be evidence of various frequencies in bond risk premia. For example, Cieslak and Povala (2011) identify a cycle factor having high predictive power for annual returns and that moves at a frequency similar to that of the CP factor, while Mueller et al. (2011) find that variance risk premia have strong predictive power for monthly bond returns.

We report a variance decomposition in Table 8. It illustrates the contribution of each shock to the variance of yield forecast errors. As is commonly found in the literature, the bulk of the variance across countries is accounted for by the level factor. However, our emphasis is on the return factors. In general, shocks to the global factor account for a tiny fraction of the variance with a contribution in the $0-16 \%$ range. In the US, shocks to the global CP factor account for at most $11 \%$ of the variance. This is consistent with the earlier impulse-response functions indicating that shocks to global risk premia had a small effect 
on yields. In addition, shocks to the local return factor generally have a small impact on the variance, with the possible exception of long-term rates in Switzerland. Hence, our results reported so far suggest that the return-forecasting factors, particularly the global factor, have a small impact on the cross-section of yields despite being strong predictors of returns. Changing the order of our variables does not significantly affect the results (see, e.g., Bikbov and Chernov, 2010, for a discussion).

For brevity, we do not report the estimated risk-neutral parameters but instead focus on the market prices of risk. Our estimates of $\lambda_{1}$ for each country are reported in Table 9. It is well-known that identifying the market prices of risk can be difficult. A common approach is to estimate them iteratively, setting insignificant $\lambda$ s equal to zero in each step and then re-estimating the model. To circumvent these issues, we impose economically generated restrictions on $\lambda$ and abstract from standard errors. The restrictions we impose on $\lambda_{1}$ imply that only the local and global factor drive risk premia and that only level shocks are priced. Negative (positive) estimates of $\lambda_{1}$ indicate that positive shocks to the state variables raise (lower) the pricing kernel. Whether this gives rise to positive or negative risk premia depends on the covariance between the shocks and the bond returns. We estimate the market price of level risk to be negative across all countries. As positive level shocks lead to lower bond returns, the negative price of risk means that exposure to level risk contributes to a positive risk premium. Simply stated, level shocks generate poor bond returns in bad times and therefore contribute to positive bond risk premia.

A problem with many term-structure models is that, due to overfitting, they produce unreasonably large maximum Sharpe ratios, as pointed out by Duffee (2010). The maximum Sharpe ratio in our Gaussian models is the conditional standard deviation of the log-pricing kernel, here $\sqrt{\operatorname{Var}_{t}\left(m_{t}\right)}=\sqrt{\lambda_{t}^{\prime} \Sigma \lambda_{t}}$. Hence, the parameterization of the market price of risk determines the conditional maximum Sharpe ratio. Figure 6 depicts the time series of maximum (annualized) Sharpe ratios for the four studied countries. The unconditional means 
of the conditional Sharpe ratios are 0.61, 0.63, 1.63, and 0.48 for Germany, Switzerland, the UK, and the US, respectively, which seem reasonable. Even though we estimate four- and five-factor models, our models do not display abnormally high Sharpe ratios, as pointed out by Duffee (2010). As we impose restrictions on the market prices of risk, $\lambda$, the problem of overfitting is mitigated.

We simulate our estimated affine term-structure models to analyze their ability to replicate the strong predictive power we find for the CP factors. We use our estimated parameter values to generate a vector of simulated state variables. Using the simulated state variables, we then compute simulated yields and finally perform the same predictive regressions as we run in data. We consider both population statistics (100,000 months) and small sample statistics (1,000 simulations of 420 observations each). The simulation results are reported in the online Appendix. The model can match the fact that FB regressions generate low predictive power, while CP factors display significant forecasting power. Furthermore, our simulations generate very similar predictive power for PC regressions and CP regressions, suggesting that it is difficult to distinguish between the predictive content of PCs and of CP factors in a simulation context.

\section{The nature of the global factor}

The ability of the global factor to predict international returns is intriguing, and naturally raises the question of its source. The natural starting point is to consider the link between macroeconomic conditions and the factor. We know from asset pricing theory that risk premia should be positive on average for assets whose returns co-vary positively with investor wellbeing. Furthermore, risk premia seem to vary countercyclically over time (e.g., Fama and French, 1989).

Figure 7 shows the lead-lag relationship between the global factor and a leading aggregate 
OECD economic indicator covering all 30 member countries. ${ }^{15}$ We keep the global factor fixed at date $t$ and then lead and lag the economic indicators. A rise in global risk premia is found to be preceded by a drop in leading indicators. Interestingly, correlations turn positive for horizons of around two years, suggesting that an increase in global risk premia is followed by improving economic conditions. Hence, while a drop in economic indicators leads an increase in risk premia, a rise in risk premia tend to lead improvement in future economic growth. Even though an increase in risk premia seems to be associated with a contemporaneous drop in economic activity, it does signal better times ahead. We demonstrate in the online Appendix that a similar picture emerges when relating local factors to local OECD leading indicators.

The positive relationship between the current global factor and future economic conditions suggests that the factor has predictive power for future economic growth. Indeed, Koijen et al. (2012) find that the US CP factor can predict economic activity as measured by the Chicago Fed National Activity Index. We evaluate this predictive power by regressing industrial production growth for the US and for the aggregate of all OECD countries on the global factor. We consider forecasting horizons of up to three years. Since it is well known that the slope of the yield curve has predictive power for growth, we compare results obtained using the global factor with those obtained using a global slope variable in the form of the US slope; the results are reported in Table 10. The global factor has significant forecasting power for US economic growth, yielding statistically significant slope coefficients and $R^{2}$ s of $7 \%, 21 \%$, and $30 \%$ for horizons of one, two, and three years, respectively. The slope factor also displays evidence of being a powerful predictor; it drives out the significance of the global factor at one- and two-year horizons, while both predictors are significant at

\footnotetext{
${ }^{15}$ The OECD leading economic indicators are time series formed by aggregating various economic indicators for each country to anticipate economic movements and turning points; examples of such indicators are consumer sentiment indicators, business climate indicators, and the purchasing managers index. Movements in leading indicators have been demonstrated to precede changes in business cycles with a lead time of 6-9 months.
} 
the three-year horizon. The second panel presents the results of predicting global growth in the form of total OECD growth. The global factor produces $R^{2}$ values of $13 \%$ and $27 \%$ for two- and three-year horizons, respectively, with statistically significant coefficients. This suggests that the global factor not only is a key driver of global risk premia but also conveys important information regarding future global growth.

Our findings are broadly consistent with those of papers that decompose yields into two parts, i.e., expected future short rates and term premia, and use these to predict economic growth. ${ }^{16}$ The general finding is that the first part, the expectation hypothesis part, mainly drives the predictive power, often driving out the significance of the term premium coefficient. However, our global factor seems to convey independent information relevant to long-horizon predictions as it remains statistically significant.

We have also predicted growth over the two subsamples, 1975-1991 and 1992-2009. Interestingly, the results differ markedly between the two subsamples. In the first subsample, the slope factor has substantial forecasting power while the global factor has weaker power. In contrast, the results are approximately reversed in the second subsample, in which the global factor has strong forecasting power. These results suggest that our risk premium factors have become increasingly important for future growth at the same time as risk premia across countries have become increasingly correlated. Overall, this suggests an increase in integration across markets.

As discussed earlier, shocks to the global factor account for very little of the variation in yield forecast errors - perhaps surprising, since this factor is a strong predictor of returns. However, a factor that causes offsetting movements in risk premia and expected future short rates can have a small effect on yield levels but still have predictive power for returns. The impulse-response analysis revealed that positive shocks to global risk premia tend to lower future short rates. We investigate this further by analyzing the relationship between the

\footnotetext{
${ }^{16}$ See, e.g., Hamilton and Kim (2002), Wright (2006), Ang et al. (2006), and Rudebusch et al. (2007).
} 
global factor and expected changes in short-term US interest rates. We use the expected three-month US rate over one year collected from the Survey of Professional Forecasters as our expectation variable. We then take the difference between the expected rate and the current three-month rate and use the expected change in short-term interest rates to analyze the lead-lag relationship between the expected change and the global factor. As the survey is conducted at the end of the first month of each quarter, we align the observed value of the

global factor at the end of the month with the survey data. For example, the survey in the first quarter of 1976 is aligned with the global factor observed at the end of January 1976. We keep the global factor fixed and then lead and lag short-rate expectations.

Figure 8 shows that expected changes in US short rates are negatively correlated with future global risk premia. For example, periods of lower expected short rates in the US, often witnessed when entering bad times, tend to lead an increase in global risk premia. The correlation between expectations of rate changes and the global factor one year forward is -0.30. Interestingly, the correlations turn positive when we consider the correlation between the current global factor and future interest rate expectations. This suggests that an increase in global risk premia is associated with a subsequent increase in expected short rates, with a lag of around two years. This is consistent with the results presented in Table 10, which indicate that the global factor positively predicts economic growth, since periods of higher growth are usually associated with the upward revision of investors' short-rate expectations. Overall, these results support our interpretation of the global factor as a business-cycle variable generating offsetting movements in risk premia and expected short rates.

\section{Conclusion}

We find evidence for time-varying bond risk premia across international markets in the form of local and global factors that predict returns but which are poorly spanned by the tradi- 
tional level, slope, and curvature factors. These local and global factors are jointly significant when predicting returns and their explanatory power is significantly higher than that of the forward rates-spot rate differentials in the classical Fama and Bliss (1987) regressions. The global factor is closely related to US bond risk premia and is demonstrated to be related to international business cycles. Our results indicate that bond risk premia are driven by both country-specific and global factors, correlations between local factors having increased over time. This increased correlation suggests increased integration across markets. Our results suggest that the global factor not only is a key driver of global risk premia but also conveys important information regarding future global growth, as it positively predicts global industrial production.

Our findings prompt us to estimate an affine no-arbitrage term-structure model in which risk premia are assumed to be driven by one local and one global factor. The estimation reveals that the two return-forecasting factors have nearly zero impact on the current crosssection of yields, despite being strong predictors of future returns. Shocks to global risk premia seem to cause offsetting movements in expected returns and expected future shortterm interest rates, leaving current yields little affected. 


\section{References}

Ang, Andrew, Monika Piazzesi, and Min Wei, 2006, What does the yield curve tell us about GDP growth?, Journal of Econometrics 131, 359-403.

Backus, David K., Silverio Foresi, and Chris I. Telmer, 2001, Affine term structure models and the forward premium anomaly, Journal of Finance 56, 279-304.

Baele, Lieven, AnnaLisa Ferrando, Peter Hördahl, Elizaveta Krylova, and Cyril Monnet, 2004, Measuring financial integration in the Euro area, Working Paper.

Bansal, Ravi, and Ivan Shaliastovich, 2010, A long-run risks explanation of predictability puzzles in bond and currency markets, Working Paper.

Bansal, Ravi, and Amir Yaron, 2004, Risks for the long run: A potential resolution of asset pricing puzzles, Journal of Finance 59, 1481-1509.

Barr, David G., and Richard Priestley, 2004, Expected returns, risk and the integration of international bond markets, Journal of International Money and Finance 23, 71-97.

Bekaert, Geert, Campbell R. Harvey, Christian T. Lundblad, and Stephan Siegel, 2011, The European union, the euro, and equity market integration, Working Paper.

Bekaert, Geert, and Robert J. Hodrick, 2001, Expectations hypotheses tests, Journal of Finance 56, 1357-1394.

Bekaert, Geert, and Xiaozheng Sandra Wang, 2009, Globalization and asset prices, Working Paper.

Bikbov, Ruslan, and Mikhail Chernov, 2010, No-arbitrage macroeconomic determinants of the yield curve, Journal of Econometrics 159, 166-182.

Brandt, Michael W., and Kevin Q. Wang, 2003, Time-varying risk aversion and unexpected inflation, Journal of Monetary Economics 50, 1457-1498.

Buraschi, Andrea, and Alexei Jiltsov, 2007, Habit formation and macroeconomic models of the term structure of interest rates, Journal of Finance 62, 3009-3063.

Campbell, John Y., and John H. Cochrane, 1999, By force of habit: A consumption-based explanation of aggregate stock market behavior, Journal of Political Economy 107, 205251.

Campbell, John Y., and Yasushi Hamao, 1992, Predictable stock returns in the United States and Japan: A study of long-term capital market integration, Journal of Finance 47, 43-69.

Cieslak, Anna, and Pavol Povala, 2011, Understanding bond risk premia, Working Paper. 
Cochrane, John H., and Monika Piazzesi, 2005, Bond risk premia, American Economic Review 95, 138-160.

Cochrane, John H., and Monika Piazzesi, 2008, Decomposing the yield curve, Working Paper.

Cooper, Ilan, and Richard Priestley, 2009, Time-varying risk premiums and the output gap, Review of Financial Studies 22, 2801-2833.

Dahlquist, Magnus, 1995, Conditional forward term premia: Some international evidence, Chapter 3 in PhD dissertation, Institute for International Economic Studies, Stockholm University.

Dai, Qiang, and Kenneth J. Singleton, 2000, Specification analysis of affine term structure models, Journal of Finance 50, 1943-1978.

Dai, Qiang, and Kenneth J. Singleton, 2002, Expectation puzzles, time-varying risk premia, and affine models of the term structure, Journal of Financial Economics 63, 415-441.

Dai, Qiang, Kenneth J. Singleton, and Wei Yang, 2004, Predictability of bond risk premia and affine term structure models, Working Paper.

Diebold, Francis X., Canlin Li, and Vivian Z. Yue, 2008, Global yield curve dynamics and interactions: A dynamic Nelson-Siegel approach, Journal of Econometrics 146, 351-363.

Driessen, Joost, Bertrand Melenberg, and Theo Nijman, 2003, Common factors in international bond returns, Journal of International Money and Finance 22, 629-656.

Duffee, Gregory R., 2002, Term premia and interest rate forecasts in affine models, Journal of Finance 57, 405-443.

Duffee, Gregory R., 2010, Sharpe ratios in term structure models, Working Paper.

Duffee, Gregory R., 2011, Information in (and not in) the term structure, Review of Financial Studies 24, 2895-2934.

Ehrmann, Michael, and Marcel Fratscher, 2005, Equal size, equal role? Interest rate interdependence between the Euro area and the United States, Economic Journal 115, 928-948.

Ehrmann, Michael, Marcel Fratscher, and Roberto Rigobon, 2011, Stocks, bonds, money markets and exchange rates: Measuring international financial transmission, forthcoming in Journal of Applied Econometrics.

Fama, Eugene F., and Robert R. Bliss, 1987, The information in long-maturity forward rates, American Economic Review 77, 680-692.

Fama, Eugene F., and Kenneth R. French, 1989, Business conditions and expected returns on stocks and bonds, Journal of Financial Economics 25, 23-49. 
Ferson, Wayne E., and Campbell R. Harvey, 1993, The risk and predictability of international equity returns, Review of Financial Studies 6, 527-566.

Fontaine, Jean-Sebastien, and Rene Garcia, 2012, Bond liquidity premia, forthcoming in the Review of Financial Studies.

Gurkaynak S. Refet, Brian Sack, and Jonathan H. Wright, 2007, The U.S. treasury yield curve: 1961 to the present, Journal of Monetary Economics 54, 2291-2304.

Hamilton, James D., and Dong Heon Kim, 2002, A re-examination of the predictability of the yield spread for real economic activity, Journal of Money, Credit and Banking 34, $340-360$.

Hardouvelis, Gikas A., 1994, The term structure spread and future changes in long and short rates in the G7 countries, Journal of Monetary Economics 33, 255-283.

Harvey, Campbell R., 1991, The world price of covariance risk, Journal of Finance 46, 111157.

Hasseltoft, Henrik, 2012, Stocks, bonds, and long-run consumption risks, Journal of Financial and Quantitative Analysis 47, 309-332.

Ilmanen, Antti, 1995, Time-varying expected returns in international bond markets, Journal of Finance 50, 481-506.

Joslin, Scott, Marcel Priebsch, and Kenneth J. Singleton, 2010, Risk premiums in dynamic term structure models with unspanned macro risks, Working Paper.

Jotikasthira, Chotibhak, Ahn Le, and Christian Lundblad, 2012, Why do term structures in different currencies comove?, Working Paper.

Kessler, Stephan, and Bernd Scherer, 2009, Varying risk premia in international markets, Journal of Banking and Finance 33, 1361-1375.

Koijen, Ralph, Hanno Lustig, and Stijn van Nieuwerburgh, 2012, The cross-section and time series of stock and bond returns, Working Paper.

Kose, Ayhan, Christopher Otrok, and Charles H. Whiteman, 2003, International business cycles: World, region, and country-specific factors, American Economic Review 93, 12161239 .

Litterman, Robert, and Josè Scheinkman, 1991, Common factors affecting bond returns, Journal of Fixed Income 1, 54-61.

Ludvigson, Sydney C., and Serena Ng, 2009, Macro factors in bond risk premia, Review of Financial Studies 22, 5027-5067. 
Lustig, Hanno, Nick Roussanov, and Adrien Verdelhan, 2011, Common risk factors in currency markets, forthcoming in the Review of Financial Studies.

Mueller, Philippe, Andrea Vedolin, and Hao Zhou, 2011, Short-run bond risk premia, Working Paper.

Nelson, Charles R., and Andrew F. Siegel, 1987, Parsimonious modeling of yield curves, Journal of Business 60, 473-489.

Newey, Whitney K., and Kenneth D. West, 1987, A simple, positive semi-definite, heteroskedasticity and autocorrelation consistent covariance matrix, Econometrica 55, 703708.

Perignon, Christophe, Daniel R. Smith, and Christophe Villa, 2007, Why common factors in international bond returns are not so common, Journal of International Money and Finance 26, 284-304.

Politis, Dimitris N., and Jospeh P. Romano, 1994, The stationary bootstrap, Journal of the American Statistal Association 89, 1303-1313.

Politis, Dimitris N., and Halbert White, 2004, Automatic block-length selection for the dependent bootstrap, Econometric Reviews 23, 53-70.

Politis, Dimitris N., Halbert White, and Andrew Patton, 2009, Correction to "Automatic block-length selection for the dependent bootstrap" by D. Politis and H. White, Econometric Reviews 28, 372-375.

Pukthuanthong, Kuntara, and Richard Roll, 2009, Global market integration: An alternative measure and its application, Journal of Financial Economics 94, 214-232.

Rudebusch Glenn, Brian Sack, and Eric Swanson, 2007, Macroeconomic implications of changes in the term premium, Federal Reserve Bank of St. Louis Review 89(4).

Wachter, Jessica A., 2006, A consumption-based model of the term structure of interest rates, Journal of Financial Economics 79, 365-399.

Wright, Jonathan, 2006, The yield curve and predicting recessions, Working Paper.

Wright, Jonathan, 2011, Term premia and inflation uncertainty: Empirical evidence from an international panel dataset, American Economic Review 101, 1514-1534. 


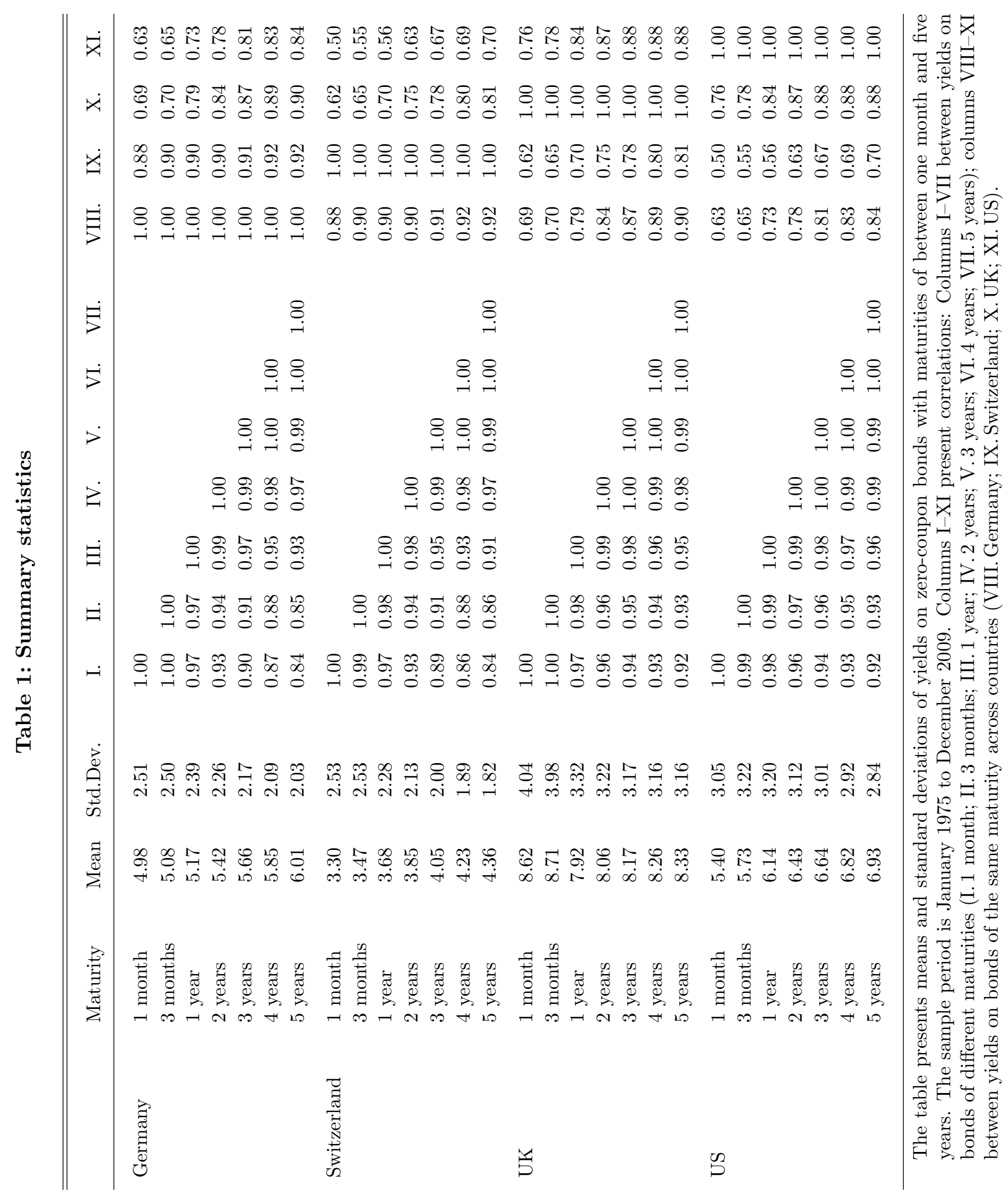




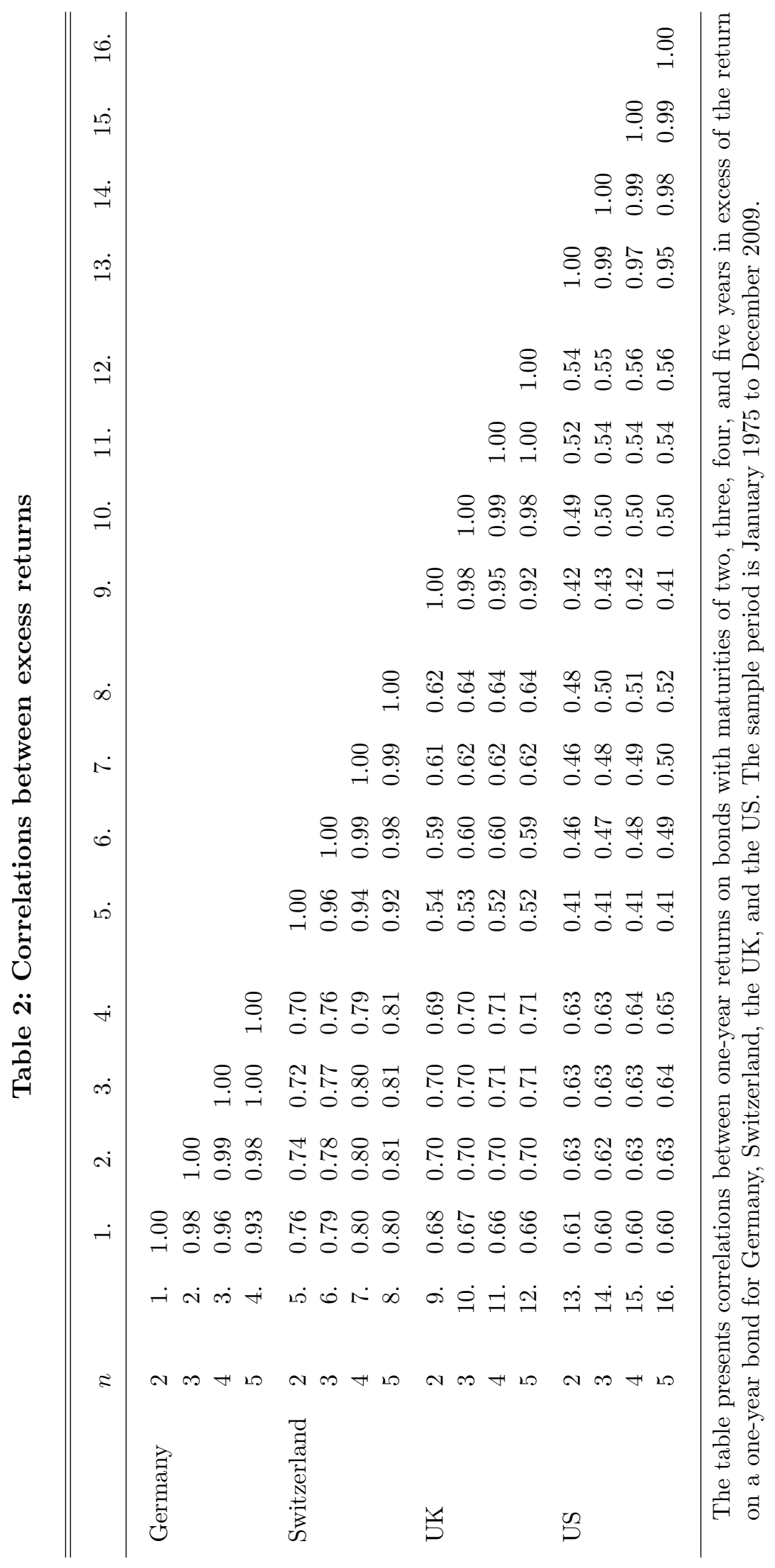


Table 3: Correlations between local and global CP factors

\begin{tabular}{lrcccc}
\hline \hline & Germany & Switzerland & UK & US & Global \\
\hline $\begin{array}{l}\text { 1975-2009 } \\
\text { Germany }\end{array}$ & 1.00 & & & & \\
Switzerland & 0.73 & 1.00 & & & \\
UK & 0.14 & 0.45 & 1.00 & & \\
US & 0.25 & 0.27 & 0.06 & 1.00 & 1.00 \\
Global & 0.41 & 0.43 & 0.20 & 0.98 & \\
1975-1991 & & & & & \\
Germany & 1.00 & & & & \\
Switzerland & 0.55 & 1.00 & & & \\
UK & -0.14 & 0.31 & 1.00 & & \\
US & 0.17 & 0.06 & -0.12 & 1.00 & \\
Global & 0.29 & 0.19 & 0.00 & 0.98 & \\
1992-2009 & & & & & \\
Germany & 1.00 & & & & \\
Switzerland & 0.76 & 1.00 & & & \\
UK & 0.54 & 0.68 & 1.00 & & \\
US & 0.30 & 0.59 & 0.52 & 1.00 & \\
Global & 0.44 & 0.69 & 0.62 & 0.99 & \\
\hline
\end{tabular}

The table presents correlations between monthly CP factors for Germany, Switzerland, the UK, and the US, and the global CP factor based on data for the full sample period (1975-2009) and two subsample periods (1975-1991 and 1992-2009). 
Table 4: Fama-Bliss and Cochrane-Piazzesi regressions

\begin{tabular}{|c|c|c|c|c|c|}
\hline & $n$ & $b_{c}^{n}$ & $R^{2}$ & $b_{c, C P}^{n}$ & $R^{2}$ \\
\hline \multirow[t]{4}{*}{ Germany } & 2 & $\begin{array}{c}0.33 \\
(0.39)\end{array}$ & $\begin{array}{c}0.02 \\
\{0.00,0.13\}\end{array}$ & $\begin{array}{c}0.40 \\
(0.13)\end{array}$ & $\begin{array}{c}0.09 \\
\{0.02,0.18\}\end{array}$ \\
\hline & 3 & $\begin{array}{c}0.55 \\
(0.45)\end{array}$ & $\begin{array}{c}0.04 \\
\{0.00,0.16\}\end{array}$ & $\begin{array}{c}0.83 \\
(0.24)\end{array}$ & $\begin{array}{c}0.11 \\
\{0.03,0.21\}\end{array}$ \\
\hline & 4 & $\begin{array}{c}0.67 \\
(0.50)\end{array}$ & $\begin{array}{c}0.05 \\
\{0.00,0.16\}\end{array}$ & $\begin{array}{c}1.22 \\
(0.34)\end{array}$ & $\begin{array}{c}0.12 \\
\{0.04,0.23\}\end{array}$ \\
\hline & 5 & $\begin{array}{c}0.76 \\
(0.55)\end{array}$ & $\begin{array}{c}0.05 \\
\{0.00,0.16\}\end{array}$ & $\begin{array}{c}1.55 \\
(0.43)\end{array}$ & $\begin{array}{c}0.13 \\
\{0.04,0.24\}\end{array}$ \\
\hline \multirow[t]{4}{*}{ Switzerland } & 2 & $\begin{array}{c}0.74 \\
(0.23)\end{array}$ & $\begin{array}{c}0.16 \\
\{0.03,0.32\}\end{array}$ & $\begin{array}{c}0.54 \\
(0.12)\end{array}$ & $\begin{array}{c}0.22 \\
\{0.07,0.42\}\end{array}$ \\
\hline & 3 & $\begin{array}{c}0.74 \\
(0.35)\end{array}$ & $\begin{array}{c}0.08 \\
\{0.00,0.23\}\end{array}$ & $\begin{array}{c}0.90 \\
(0.23)\end{array}$ & $\begin{array}{c}0.20 \\
\{0.05,0.37\}\end{array}$ \\
\hline & 4 & $\begin{array}{c}0.76 \\
(0.46)\end{array}$ & $\begin{array}{c}0.06 \\
\{0.00,0.22\}\end{array}$ & $\begin{array}{c}1.19 \\
(0.30)\end{array}$ & $\begin{array}{c}0.19 \\
\{0.05,0.36\}\end{array}$ \\
\hline & 5 & $\begin{array}{c}0.75 \\
(0.61)\end{array}$ & $\begin{array}{c}0.04 \\
\{0.00,0.21\}\end{array}$ & $\begin{array}{c}1.37 \\
(0.36)\end{array}$ & $\begin{array}{c}0.17 \\
\{0.04,0.34\}\end{array}$ \\
\hline \multirow[t]{4}{*}{ UK } & 2 & $\begin{array}{c}0.30 \\
(0.26)\end{array}$ & $\begin{array}{c}0.02 \\
\{0.00,0.10\}\end{array}$ & $\begin{array}{c}0.39 \\
(0.16)\end{array}$ & $\begin{array}{c}0.08 \\
\{0.01,0.19\}\end{array}$ \\
\hline & 3 & $\begin{array}{c}0.39 \\
(0.34)\end{array}$ & $\begin{array}{c}0.02 \\
\{0.00,0.09\}\end{array}$ & $\begin{array}{c}0.85 \\
(0.28)\end{array}$ & $\begin{array}{c}0.12 \\
\{0.03,0.25\}\end{array}$ \\
\hline & 4 & $\begin{array}{c}0.37 \\
(0.42)\end{array}$ & $\begin{array}{c}0.01 \\
\{0.00,0.07\}\end{array}$ & $\begin{array}{c}1.24 \\
(0.40)\end{array}$ & $\begin{array}{c}0.13 \\
\{0.03,0.26\}\end{array}$ \\
\hline & 5 & $\begin{array}{c}0.30 \\
(0.46)\end{array}$ & $\begin{array}{c}0.00 \\
\{0.00,0.06\}\end{array}$ & $\begin{array}{c}1.52 \\
(0.52)\end{array}$ & $\begin{array}{c}0.12 \\
\{0.03,0.25\}\end{array}$ \\
\hline \multirow[t]{4}{*}{ US } & 2 & $\begin{array}{c}0.73 \\
(0.30)\end{array}$ & $\begin{array}{c}0.08 \\
\{0.00,0.18\}\end{array}$ & $\begin{array}{c}0.44 \\
(0.09)\end{array}$ & $\begin{array}{c}0.20 \\
\{0.07,0.31\}\end{array}$ \\
\hline & 3 & $\begin{array}{c}1.05 \\
(0.37)\end{array}$ & $\begin{array}{c}0.10 \\
\{0.01,0.22\}\end{array}$ & $\begin{array}{c}0.86 \\
(0.18)\end{array}$ & $\begin{array}{c}0.22 \\
\{0.07,0.35\}\end{array}$ \\
\hline & 4 & $\begin{array}{c}1.23 \\
(0.46)\end{array}$ & $\begin{array}{c}0.11 \\
\{0.01,0.23\}\end{array}$ & $\begin{array}{c}1.26 \\
(0.25)\end{array}$ & $\begin{array}{c}0.24 \\
\{0.08,0.38\}\end{array}$ \\
\hline & 5 & $\begin{array}{c}0.88 \\
(0.55)\end{array}$ & $\begin{array}{c}0.04 \\
\{0.00,0.13\}\end{array}$ & $\begin{array}{c}1.44 \\
(0.32)\end{array}$ & $\begin{array}{c}0.21 \\
\{0.06,0.35\}\end{array}$ \\
\hline
\end{tabular}

The table presents the results of Fama-Bliss (1987) and Cochrane-Piazzesi (2005) regressions, corresponding to regression equations (3) and (4). Estimates of constant terms are not tabulated. The sample period is January 1975 to December 2009. Point estimates are reported with Newey and West (1987) standard errors, accounting for conditional heteroscedasticity and serial correlation up to twelve lags, in parentheses. Adjusted $R^{2}$ values are reported with $90 \%$ bootstrapped confidence intervals in curly brackets. 
Table 5: Level, slope, and curvature regressions

\begin{tabular}{|c|c|c|c|c|c|}
\hline & $n$ & $b_{c, \text { Level }}^{n}$ & $b_{c, \text { Slope }}^{n}$ & $b_{c, \text { Curvature }}^{n}$ & $R^{2}$ \\
\hline \multirow[t]{8}{*}{ Germany } & \multirow[t]{2}{*}{2} & 0.04 & 0.53 & 0.19 & 0.06 \\
\hline & & $(0.05)$ & $(0.33)$ & $(1.75)$ & $\{0.02,0.28\}$ \\
\hline & \multirow[t]{2}{*}{3} & 0.08 & 1.11 & 0.70 & 0.08 \\
\hline & & $(0.09)$ & $(0.61)$ & $(3.20)$ & $\{0.03,0.29\}$ \\
\hline & \multirow[t]{2}{*}{4} & 0.10 & 1.70 & 1.50 & 0.09 \\
\hline & & $(0.12)$ & $(0.85)$ & $(4.33)$ & $\{0.03,0.29\}$ \\
\hline & \multirow[t]{2}{*}{5} & 0.11 & 2.28 & 2.52 & 0.10 \\
\hline & & $(0.14)$ & $(1.06)$ & $(5.29)$ & $\{0.04,0.29\}$ \\
\hline \multirow[t]{8}{*}{ Switzerland } & \multirow[t]{2}{*}{2} & 0.10 & 1.16 & -1.73 & 0.25 \\
\hline & & $(0.05)$ & $(0.29)$ & $(1.01)$ & $\{0.11,0.47\}$ \\
\hline & \multirow[t]{2}{*}{3} & 0.16 & 1.83 & -0.72 & 0.19 \\
\hline & & $(0.10)$ & $(0.54)$ & $(1.98)$ & $\{0.07,0.40\}$ \\
\hline & \multirow[t]{2}{*}{4} & 0.20 & 2.48 & 0.79 & 0.19 \\
\hline & & $(0.14)$ & $(0.68)$ & $(2.76)$ & $\{0.06,0.40\}$ \\
\hline & \multirow[t]{2}{*}{5} & 0.25 & 2.77 & 1.74 & 0.17 \\
\hline & & $(0.17)$ & $(0.80)$ & $(3.36)$ & $\{0.06,0.38\}$ \\
\hline \multirow[t]{8}{*}{ UK } & \multirow[t]{2}{*}{2} & 0.03 & 0.33 & 1.67 & 0.04 \\
\hline & & $(0.04)$ & $(0.31)$ & $(1.34)$ & $\{0.01,0.21\}$ \\
\hline & \multirow[t]{2}{*}{3} & 0.07 & 0.51 & 3.68 & 0.05 \\
\hline & & $(0.07)$ & $(0.56)$ & $(2.39)$ & $\{0.01,0.22\}$ \\
\hline & \multirow[t]{2}{*}{4} & 0.11 & 0.69 & 4.83 & 0.05 \\
\hline & & $(0.10)$ & $(0.80)$ & $(3.33)$ & $\{0.01,0.23\}$ \\
\hline & \multirow[t]{2}{*}{5} & 0.15 & 0.92 & 4.92 & 0.05 \\
\hline & & $(0.13)$ & $(1.00)$ & $(4.14)$ & $\{0.01,0.23\}$ \\
\hline \multirow[t]{8}{*}{ US } & \multirow[t]{2}{*}{2} & 0.04 & 0.92 & 2.29 & 0.14 \\
\hline & & $(0.04)$ & $(0.35)$ & $(1.28)$ & $\{0.05,0.32\}$ \\
\hline & \multirow[t]{2}{*}{3} & 0.05 & 1.78 & 4.45 & 0.13 \\
\hline & & $(0.08)$ & $(0.69)$ & $(2.40)$ & $\{0.04,0.31\}$ \\
\hline & \multirow[t]{2}{*}{4} & 0.05 & 2.73 & 6.12 & 0.15 \\
\hline & & $(0.11)$ & $(0.96)$ & $(3.39)$ & $\{0.05,0.32\}$ \\
\hline & \multirow[t]{2}{*}{5} & 0.04 & 3.43 & 6.48 & 0.15 \\
\hline & & $(0.14)$ & $(1.17)$ & $(4.22)$ & $\{0.05,0.32\}$ \\
\hline
\end{tabular}

The table presents results of principal-component regressions, corresponding to regression equation (5). Estimates of constant terms are not tabulated. The sample period is January 1975 to December 2009. The first three PCs of the yield covariance matrix are referred to as level, slope, and curvature. Point estimates are reported with Newey and West (1987) standard errors, accounting for conditional heteroscedasticity and serial correlation up to twelve lags, in parentheses. Adjusted $R^{2}$ values are reported with $90 \%$ bootstrapped confidence intervals in curly brackets. 
Table 6: Local and global Cochrane-Piazzesi regressions

\begin{tabular}{|c|c|c|c|c|c|c|c|c|c|}
\hline & $n$ & $b_{c, C P}^{n}$ & $R^{2}$ & $b_{c, G C P}^{n}$ & $R^{2}$ & $b_{c, C P}^{n}$ & $b_{c, G C P}^{n}$ & $R^{2}$ & Wald \\
\hline \multirow[t]{8}{*}{ Germany } & \multirow[t]{2}{*}{2} & 0.40 & 0.09 & 0.48 & 0.20 & 0.18 & 0.48 & 0.21 & \multirow[t]{2}{*}[0.00]{} \\
\hline & & $(0.13)$ & $\{0.02,0.18\}$ & $(0.09)$ & $\{0.09,0.31\}$ & $(0.12)$ & $(0.10)$ & $\{0.11,0.35\}$ & \\
\hline & \multirow[t]{2}{*}{3} & 0.83 & 0.11 & 0.90 & 0.20 & 0.45 & 0.90 & 0.23 & \multirow[t]{2}{*}[0.00]{} \\
\hline & & $(0.24)$ & $\{0.03,0.21\}$ & $(0.16)$ & $\{0.10,0.31\}$ & $(0.24)$ & $(0.17)$ & $\{0.14,0.36\}$ & \\
\hline & \multirow[t]{2}{*}{4} & 1.22 & 0.12 & 1.24 & 0.20 & 0.70 & 1.24 & 0.23 & \multirow[t]{2}{*}[0.00]{} \\
\hline & & $(0.34)$ & $\{0.04,0.23\}$ & $(0.23)$ & $\{0.11,0.29\}$ & $(0.35)$ & $(0.24)$ & $\{0.15,0.36\}$ & \\
\hline & \multirow[t]{2}{*}{5} & 1.55 & 0.13 & 1.54 & 0.20 & 0.92 & 1.54 & 0.23 & \multirow[t]{2}{*}[0.00]{} \\
\hline & & $(0.43)$ & $\{0.04,0.24\}$ & $(0.28)$ & $\{0.11,0.29\}$ & $(0.44)$ & $(0.30)$ & $\{0.15,0.35\}$ & \\
\hline \multirow[t]{8}{*}{ Switzerland } & \multirow[t]{2}{*}{2} & 0.54 & 0.22 & 0.59 & 0.20 & 0.39 & 0.59 & 0.30 & \multirow[t]{2}{*}[0.00]{} \\
\hline & & $(0.12)$ & $\{0.07,0.42\}$ & $(0.11)$ & $\{0.12,0.32\}$ & $(0.15)$ & $(0.12)$ & $\{0.17,0.45\}$ & \\
\hline & \multirow[t]{2}{*}{3} & 0.90 & 0.20 & 1.01 & 0.19 & 0.63 & 1.01 & 0.27 & \multirow[t]{2}{*}[0.00]{} \\
\hline & & $(0.23)$ & $\{0.05,0.37\}$ & $(0.22)$ & $\{0.11,0.32\}$ & $(0.27)$ & $(0.24)$ & $\{0.16,0.43\}$ & \\
\hline & \multirow[t]{2}{*}{4} & 1.19 & 0.19 & 1.36 & 0.19 & 0.83 & 1.36 & 0.27 & \multirow[t]{2}{*}[0.00]{} \\
\hline & & $(0.30)$ & $\{0.05,0.36\}$ & $(0.31)$ & $\{0.10,0.32\}$ & $(0.36)$ & $(0.34)$ & $\{0.15,0.44\}$ & \\
\hline & \multirow[t]{2}{*}{5} & 1.37 & 0.17 & 1.66 & 0.20 & 0.91 & 1.66 & 0.26 & \multirow[t]{2}{*}[0.00]{} \\
\hline & & $(0.36)$ & $\{0.04,0.34\}$ & $(0.39)$ & $\{0.10,0.33\}$ & $(0.43)$ & $(0.42)$ & $\{0.15,0.42\}$ & \\
\hline \multirow[t]{8}{*}{ UK } & \multirow[t]{2}{*}{2} & 0.39 & 0.08 & 0.38 & 0.08 & 0.32 & 0.38 & 0.14 & \multirow[t]{2}{*}[0.00]{} \\
\hline & & $(0.16)$ & $\{0.01,0.19\}$ & $(0.15)$ & $\{0.02,0.24\}$ & $(0.13)$ & $(0.14)$ & $\{0.04,0.32\}$ & \\
\hline & \multirow[t]{2}{*}{3} & 0.85 & 0.12 & 0.74 & 0.10 & 0.72 & 0.74 & 0.18 & \multirow[t]{2}{*}[0.00]{} \\
\hline & & $(0.28)$ & $\{0.03,0.25\}$ & $(0.28)$ & $\{0.02,0.25\}$ & $(0.23)$ & $(0.26)$ & $\{0.05,0.36\}$ & \\
\hline & \multirow[t]{2}{*}{4} & 1.24 & 0.13 & 1.13 & 0.12 & 1.05 & 1.13 & 0.20 & \multirow[t]{2}{*}[0.00]{} \\
\hline & & $(0.40)$ & $\{0.03,0.26\}$ & $(0.39)$ & $\{0.03,0.26\}$ & $(0.32)$ & $(0.35)$ & $\{0.07,0.38\}$ & \\
\hline & \multirow[t]{2}{*}{5} & 1.52 & 0.12 & 1.50 & 0.13 & 1.25 & 1.50 & 0.21 & \multirow[t]{2}{*}[0.00]{} \\
\hline & & $(0.52)$ & $\{0.03,0.25\}$ & $(0.47)$ & $\{0.04,0.26\}$ & $(0.41)$ & $(0.42)$ & $\{0.07,0.37\}$ & \\
\hline \multirow[t]{8}{*}{ US } & 2 & 0.44 & 0.20 & 0.59 & 0.20 & 0.16 & 0.59 & 0.20 & {$[0.00]$} \\
\hline & & $(0.09)$ & $\{0.07,0.31\}$ & $(0.13)$ & $\{0.07,0.32\}$ & $(0.46)$ & $(0.13)$ & $\{0.08,0.33\}$ & \\
\hline & 3 & 0.86 & 0.22 & 1.15 & 0.21 & 0.71 & 1.15 & 0.22 & {$[0.00]$} \\
\hline & & $(0.18)$ & $\{0.07,0.35\}$ & $(0.27)$ & $\{0.06,0.37\}$ & $(0.84)$ & $(0.25)$ & $\{0.07,0.37\}$ & \\
\hline & 4 & 1.26 & 0.24 & 1.67 & 0.23 & 1.16 & 1.67 & 0.24 & {$[0.00]$} \\
\hline & & $(0.25)$ & $\{0.08,0.38\}$ & $(0.38)$ & $\{0.07,0.39\}$ & $(1.10)$ & $(0.36)$ & $\{0.09,0.40\}$ & \\
\hline & 5 & 1.44 & 0.21 & 1.92 & 0.21 & 1.17 & 1.92 & 0.21 & {$[0.00]$} \\
\hline & & $(0.32)$ & $\{0.06,0.35\}$ & $(0.48)$ & $\{0.06,0.36\}$ & (1.38) & $(0.45)$ & $\{0.07,0.37\}$ & \\
\hline
\end{tabular}

The table presents the results of local and global Cochrane-Piazzesi (2005) regressions, corresponding to regression equations (4), (6), and (7). Estimates of constant terms are not tabulated. When both local and global CP factors are included, the local factor is orthogonalized versus the local factor. The sample period is January 1975 to December 2009. Point estimates are reported with Newey and West (1987) standard errors, accounting for conditional heteroscedasticity and serial correlation up to twelve lags, in parentheses. Adjusted $R^{2}$ values are reported with $90 \%$ bootstrapped confidence intervals in curly brackets. P-values from Wald tests of joint significance are presented in square brackets. 
Table 7: US dollar excess return regressions

\begin{tabular}{|c|c|c|c|c|c|}
\hline & $n$ & $b_{i, G C P}^{n}$ & $R^{2}$ & $b_{i, F X G C P}^{n}$ & $R^{2}$ \\
\hline \multirow[t]{8}{*}{ EUR/USD } & \multirow[t]{2}{*}{2} & 2.10 & 0.05 & 1.09 & 0.16 \\
\hline & & $(1.22)$ & $\{0.00,0.16\}$ & $(0.24)$ & $\{0.04,0.27\}$ \\
\hline & \multirow[t]{2}{*}{3} & 2.52 & 0.07 & 1.19 & 0.17 \\
\hline & & $(1.24)$ & $\{0.01,0.19\}$ & $(0.25)$ & $\{0.05,0.29\}$ \\
\hline & \multirow[t]{2}{*}{4} & 2.86 & 0.09 & 1.27 & 0.19 \\
\hline & & $(1.27)$ & $\{0.01,0.21\}$ & $(0.25)$ & $\{0.06,0.30\}$ \\
\hline & \multirow[t]{2}{*}{5} & 3.16 & 0.10 & 1.35 & 0.20 \\
\hline & & $(1.29)$ & $\{0.02,0.23\}$ & $(0.25)$ & $\{0.07,0.31\}$ \\
\hline \multirow[t]{8}{*}{ CHF/USD } & \multirow[t]{2}{*}{2} & 2.08 & 0.04 & 1.14 & 0.14 \\
\hline & & $(1.28)$ & $\{0.00,0.15\}$ & $(0.21)$ & $\{0.04,0.26\}$ \\
\hline & \multirow[t]{2}{*}{3} & 2.50 & 0.06 & 1.25 & 0.16 \\
\hline & & (1.28) & $\{0.00,0.17\}$ & $(0.22)$ & $\{0.06,0.28\}$ \\
\hline & \multirow[t]{2}{*}{4} & 2.85 & 0.07 & 1.34 & 0.18 \\
\hline & & $(1.28)$ & $\{0.00,0.19\}$ & $(0.22)$ & $\{0.07,0.29\}$ \\
\hline & \multirow[t]{2}{*}{5} & 3.15 & 0.08 & 1.42 & 0.19 \\
\hline & & $(1.29)$ & $\{0.01,0.21\}$ & $(0.23)$ & $\{0.08,0.30\}$ \\
\hline \multirow[t]{8}{*}{ GBP/USD } & \multirow[t]{2}{*}{2} & 0.36 & 0.00 & 0.55 & 0.04 \\
\hline & & (1.08) & $\{0.00,0.05\}$ & $(0.34)$ & $\{0.00,0.18\}$ \\
\hline & \multirow[t]{2}{*}{3} & 0.72 & 0.00 & 0.60 & 0.05 \\
\hline & & $(1.04)$ & $\{0.00,0.07\}$ & $(0.33)$ & $\{0.00,0.18\}$ \\
\hline & \multirow[t]{2}{*}{4} & 1.10 & 0.01 & 0.65 & 0.06 \\
\hline & & $(1.04)$ & $\{0.00,0.09\}$ & $(0.33)$ & $\{0.00,0.17\}$ \\
\hline & \multirow[t]{2}{*}{5} & 1.47 & 0.02 & 0.69 & 0.06 \\
\hline & & (1.05) & $\{0.00,0.10\}$ & $(0.33)$ & $\{0.00,0.17\}$ \\
\hline
\end{tabular}

The table presents results of regressing annual US dollar excess returns on bonds with maturities of two to five years onto the global factors GCP and FXGCP. Estimates of constant terms are not tabulated. The sample period is January 1975 to December 2009. Point estimates are reported with Newey and West (1987) standard errors, accounting for conditional heteroscedasticity and serial correlation up to twelve lags, in parentheses. Adjusted $R^{2}$ values are reported with $90 \%$ bootstrapped confidence intervals in curly brackets. 
Table 8: Variance decompositions

\begin{tabular}{|c|c|c|c|c|}
\hline & Variable & Horizon & 1 month & 5 year \\
\hline \multirow[t]{10}{*}{ Germany } & Local CP & 1 & 0.00 & 0.06 \\
\hline & & 120 & 0.07 & 0.17 \\
\hline & Global CP & 1 & 0.00 & 0.01 \\
\hline & & 120 & 0.03 & 0.02 \\
\hline & Level & 1 & 0.59 & 0.74 \\
\hline & & 120 & 0.57 & 0.47 \\
\hline & Slope & 1 & 0.39 & 0.15 \\
\hline & & 120 & 0.18 & 0.05 \\
\hline & Curvature & 1 & 0.02 & 0.04 \\
\hline & & 120 & 0.15 & 0.29 \\
\hline \multirow[t]{10}{*}{ Switzerland } & Local CP & 1 & 0.04 & 0.28 \\
\hline & & 120 & 0.04 & 0.16 \\
\hline & Global CP & 1 & 0.03 & 0.11 \\
\hline & & 120 & 0.16 & 0.03 \\
\hline & Level & 1 & 0.76 & 0.55 \\
\hline & & 120 & 0.65 & 0.73 \\
\hline & Slope & 1 & 0.16 & 0.06 \\
\hline & & 120 & 0.10 & 0.07 \\
\hline & Curvature & 1 & 0.01 & 0.00 \\
\hline & & 120 & 0.05 & 0.01 \\
\hline \multirow[t]{10}{*}{ UK } & Local CP & 1 & 0.03 & 0.16 \\
\hline & & 120 & 0.07 & 0.12 \\
\hline & Global CP & 1 & 0.00 & 0.02 \\
\hline & & 120 & 0.01 & 0.02 \\
\hline & Level & 1 & 0.69 & 0.64 \\
\hline & & 120 & 0.58 & 0.53 \\
\hline & Slope & 1 & 0.26 & 0.15 \\
\hline & & 120 & 0.23 & 0.20 \\
\hline & Curvature & 1 & 0.02 & 0.03 \\
\hline & & 120 & 0.11 & 0.13 \\
\hline \multirow[t]{8}{*}{ US } & Global CP & 1 & 0.03 & 0.03 \\
\hline & & 120 & 0.11 & 0.01 \\
\hline & Level & 1 & 0.63 & 0.81 \\
\hline & & 120 & 0.57 & 0.80 \\
\hline & Slope & 1 & 0.30 & 0.12 \\
\hline & & 120 & 0.04 & 0.14 \\
\hline & Curvature & 1 & 0.04 & 0.04 \\
\hline & & 120 & 0.28 & 0.05 \\
\hline
\end{tabular}

The table presents variance decompositions of yield forecast errors, attributed to each state variable at horizons of one month and 120 months for yields on a one-month and a five-year bond. 
Table 9: Time-varying risks in the affine models including local and global factors

\begin{tabular}{|c|c|c|c|c|c|c|}
\hline & & & & $\lambda_{1}$ & & \\
\hline \multirow[t]{5}{*}{ Germany } & Local CP & 0 & 0 & 0 & 0 & 0 \\
\hline & Global CP & 0 & 0 & 0 & 0 & 0 \\
\hline & Level & -0.081 & -0.146 & 0 & 0 & 0 \\
\hline & Slope & 0 & 0 & 0 & 0 & 0 \\
\hline & Curvature & 0 & 0 & 0 & 0 & 0 \\
\hline \multirow[t]{5}{*}{ Switzerland } & Local CP & 0 & 0 & 0 & 0 & 0 \\
\hline & Global CP & 0 & 0 & 0 & 0 & 0 \\
\hline & Level & -0.070 & -0.119 & 0 & 0 & 0 \\
\hline & Slope & 0 & 0 & 0 & 0 & 0 \\
\hline & Curvature & 0 & 0 & 0 & 0 & 0 \\
\hline \multirow[t]{5}{*}{ UK } & Local CP & 0 & 0 & 0 & 0 & 0 \\
\hline & Global CP & 0 & 0 & 0 & 0 & 0 \\
\hline & Level & -0.038 & -0.042 & 0 & 0 & 0 \\
\hline & Slope & 0 & 0 & 0 & 0 & 0 \\
\hline & Curvature & 0 & 0 & 0 & 0 & 0 \\
\hline \multirow[t]{4}{*}{ US } & Global CP & & 0 & 0 & 0 & 0 \\
\hline & Level & & -0.069 & 0 & 0 & 0 \\
\hline & Slope & & 0 & 0 & 0 & 0 \\
\hline & Curvature & & 0 & 0 & 0 & 0 \\
\hline
\end{tabular}

The table presents the estimated $\lambda_{1}$ matrices in the affine models including local and global factors for yields on bonds with maturities of one month, three months, and one to five years. Germany, Switzerland, and the UK have five state variables (i.e., $C P_{c, t}, G C P_{t}$, Level $_{c, t}$, Slope $_{c, t}$, and Curvature $_{c, t}$ ), whereas the US has four state variables (i.e., $G C P_{t}$, Level $_{c, t}$, Slope $_{c, t}$, and Curvature $e_{c, t}$ ). The parameters in $\delta_{0}, \delta_{1}, \rho^{*}$, and $\lambda_{0}$ are estimated in a first step by minimizing the mean-squared difference between model and data yields as in equation (19), but are not tabulated. The parameters in $\lambda_{1}$ are estimated in a second step by minimizing the mean-squared difference between model-implied and estimated regression coefficients. The $\lambda_{1}$ matrix for Germany, Switzerland, and the UK is restricted as in equation (17), and for the US is restricted as in equation (18). See Section 3.3 for estimation details. The sample period is January 1975 to December 2009. 
Table 10: Predictability of industrial production growth

\begin{tabular}{|c|c|c|c|c|}
\hline & Horizon & US slope & Global CP & $R^{2}$ \\
\hline \multirow[t]{18}{*}{ US } & 1 & 1.30 & & 0.14 \\
\hline & & $(0.29)$ & & $\{0.04,0.27\}$ \\
\hline & 1 & & 0.80 & 0.07 \\
\hline & & & $(0.43)$ & $\{0.00,0.21\}$ \\
\hline & 1 & 1.18 & 0.16 & 0.14 \\
\hline & & $(0.53)$ & $(0.61)$ & $\{0.06,0.30\}$ \\
\hline & 2 & 1.27 & & 0.25 \\
\hline & & $(0.30)$ & & $\{0.07,0.42\}$ \\
\hline & 2 & & 1.01 & 0.21 \\
\hline & & & $(0.30)$ & $\{0.06,0.35\}$ \\
\hline & 2 & 0.91 & 0.48 & 0.28 \\
\hline & & $(0.33)$ & $(0.28)$ & $\{0.11,0.45\}$ \\
\hline & 3 & 1.05 & & 0.27 \\
\hline & & $(0.27)$ & & $\{0.08,0.45\}$ \\
\hline & 3 & & 0.99 & 0.30 \\
\hline & & & $(0.24)$ & $\{0.14,0.45\}$ \\
\hline & 3 & 0.57 & 0.67 & 0.35 \\
\hline & & $(0.24)$ & $(0.21)$ & $\{0.18,0.54\}$ \\
\hline \multirow[t]{18}{*}{ OECD } & 1 & 0.78 & & 0.06 \\
\hline & & $(0.25)$ & & $\{0.01,0.15\}$ \\
\hline & 1 & & 0.50 & 0.03 \\
\hline & & & $(0.41)$ & $\{0.00,0.12\}$ \\
\hline & 1 & 0.67 & 0.15 & 0.06 \\
\hline & & $(0.45)$ & $(0.59)$ & $\{0.03,0.22\}$ \\
\hline & 2 & 0.99 & & 0.22 \\
\hline & & $(0.28)$ & & $\{0.07,0.34\}$ \\
\hline & 2 & & 0.67 & 0.13 \\
\hline & & & $(0.29)$ & $\{0.02,0.26\}$ \\
\hline & 2 & 0.86 & 0.17 & 0.23 \\
\hline & & $(0.21)$ & $(0.23)$ & $\{0.08,0.35\}$ \\
\hline & 3 & 0.89 & & 0.32 \\
\hline & & $(0.21)$ & & $\{0.18,0.46\}$ \\
\hline & 3 & & 0.71 & 0.27 \\
\hline & & & $(0.19)$ & $\{0.12,0.38\}$ \\
\hline & 3 & 0.63 & 0.35 & 0.36 \\
\hline & & $(0.17)$ & $(0.13)$ & $\{0.21,0.48\}$ \\
\hline
\end{tabular}

The table presents the results of predictability regressions of industrial production growth using the slope of the US yield curve and the global CP factor as predictors. The regressions are run for annualized growth in industrial production over horizons of one, two, and three years for the US and all OECD countries. Estimates of constant terms are not tabulated. The sample period is January 1975 to December 2009. Point estimates are reported with Newey and West (1987) standard errors, accounting for conditional heteroscedasticity and serial correlation up to and including the forecasting horizon, in parentheses. Adjusted $R^{2}$ values are reported with $90 \%$ bootstrapped confidence intervals in curly brackets. 


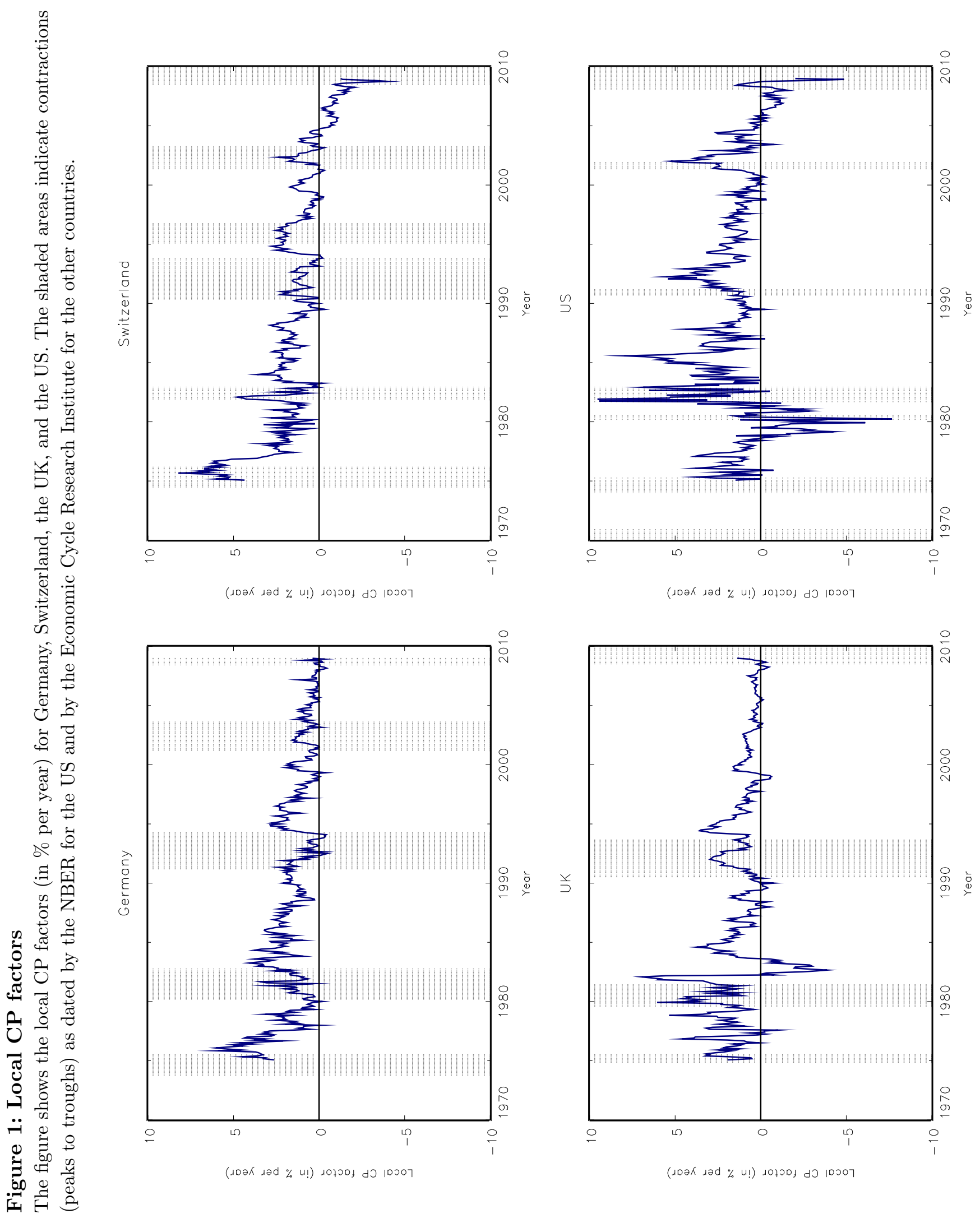




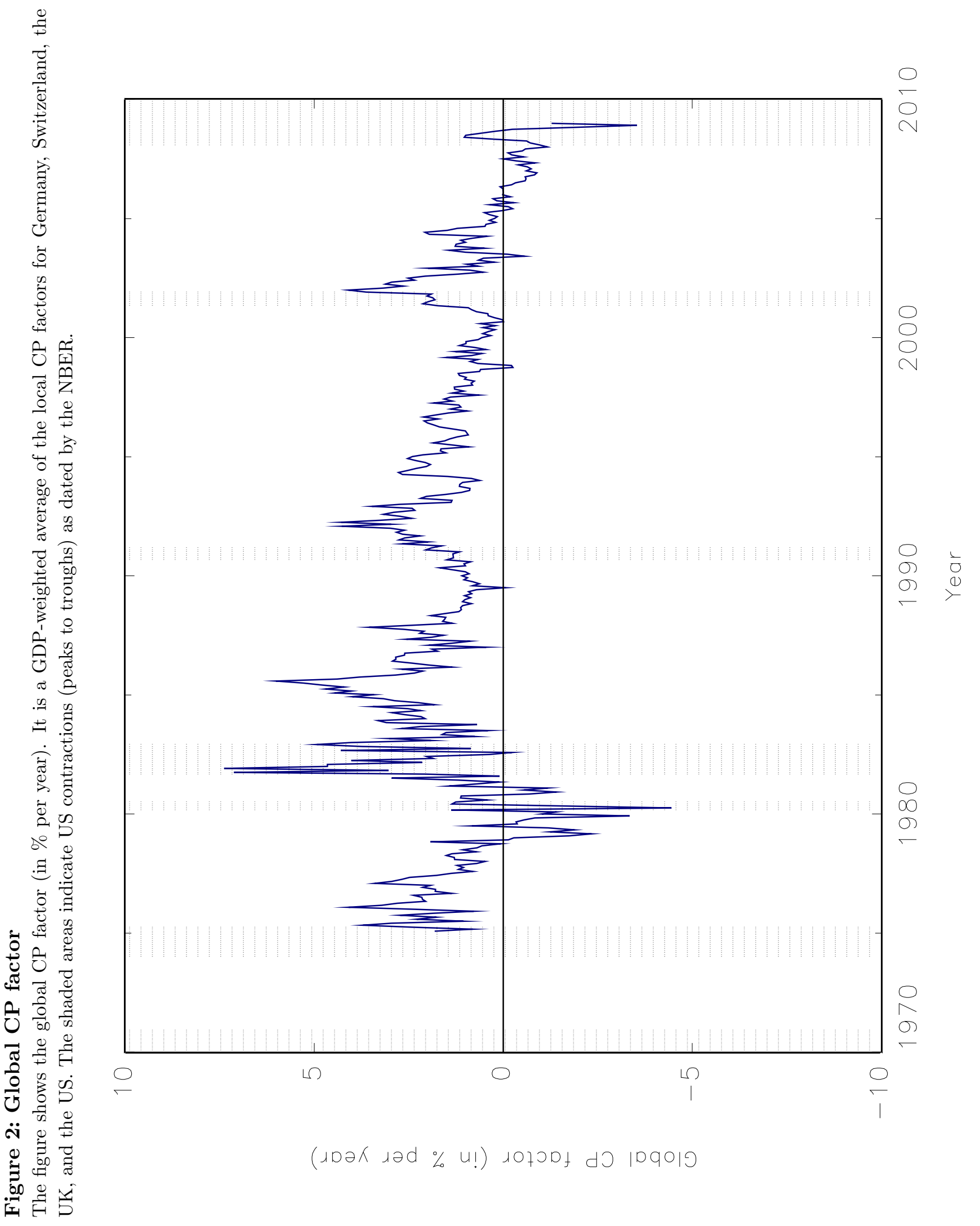




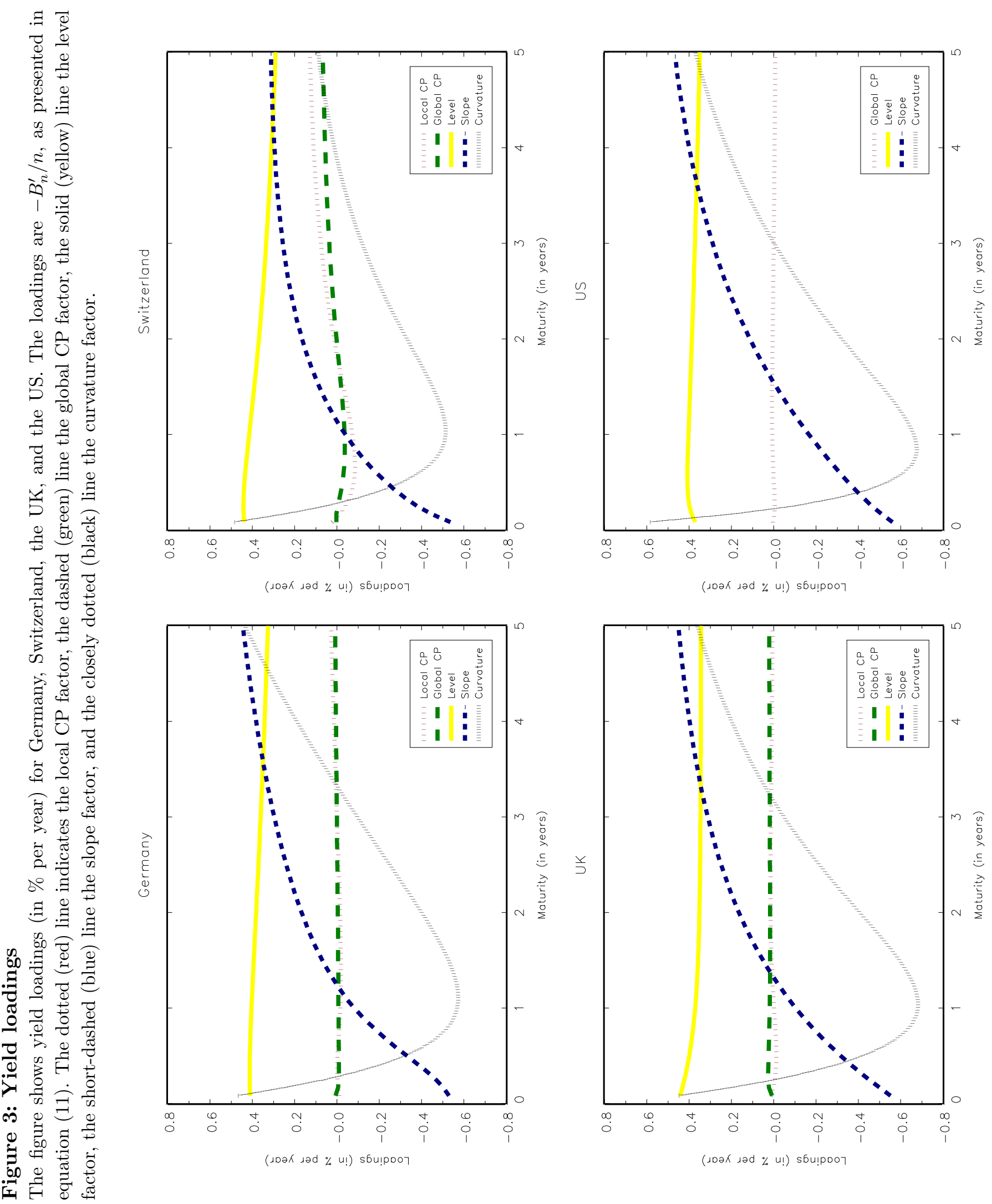




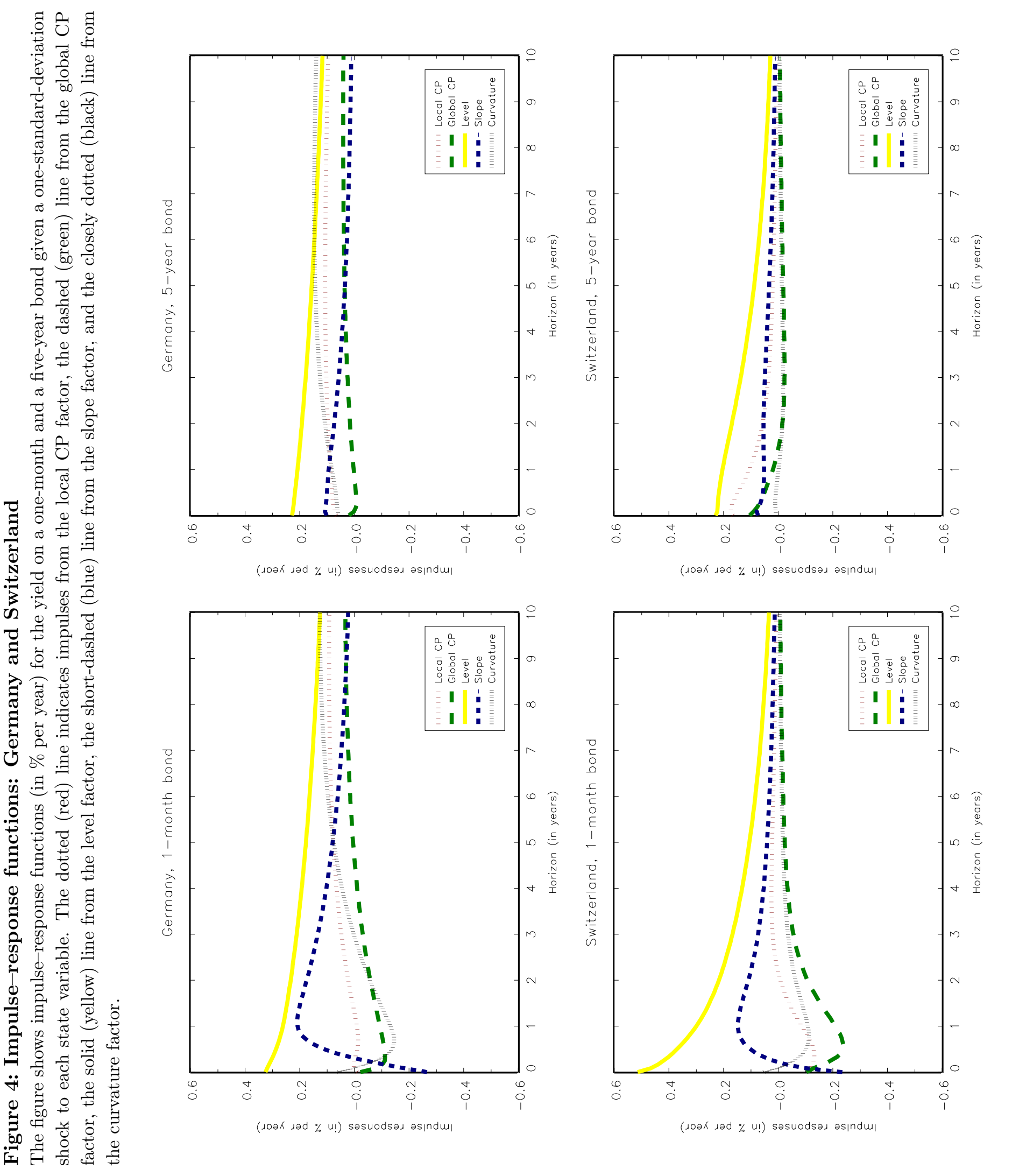



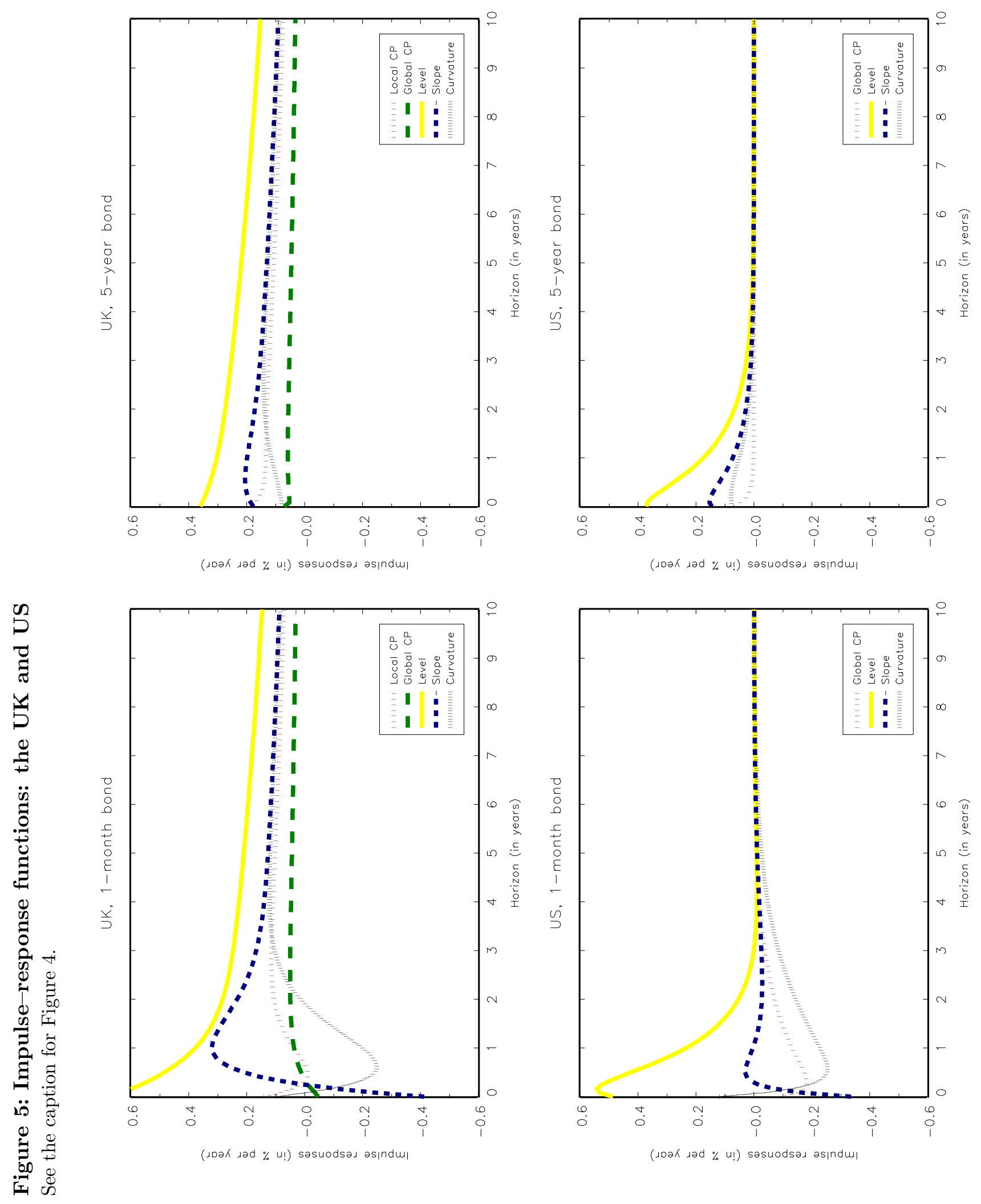


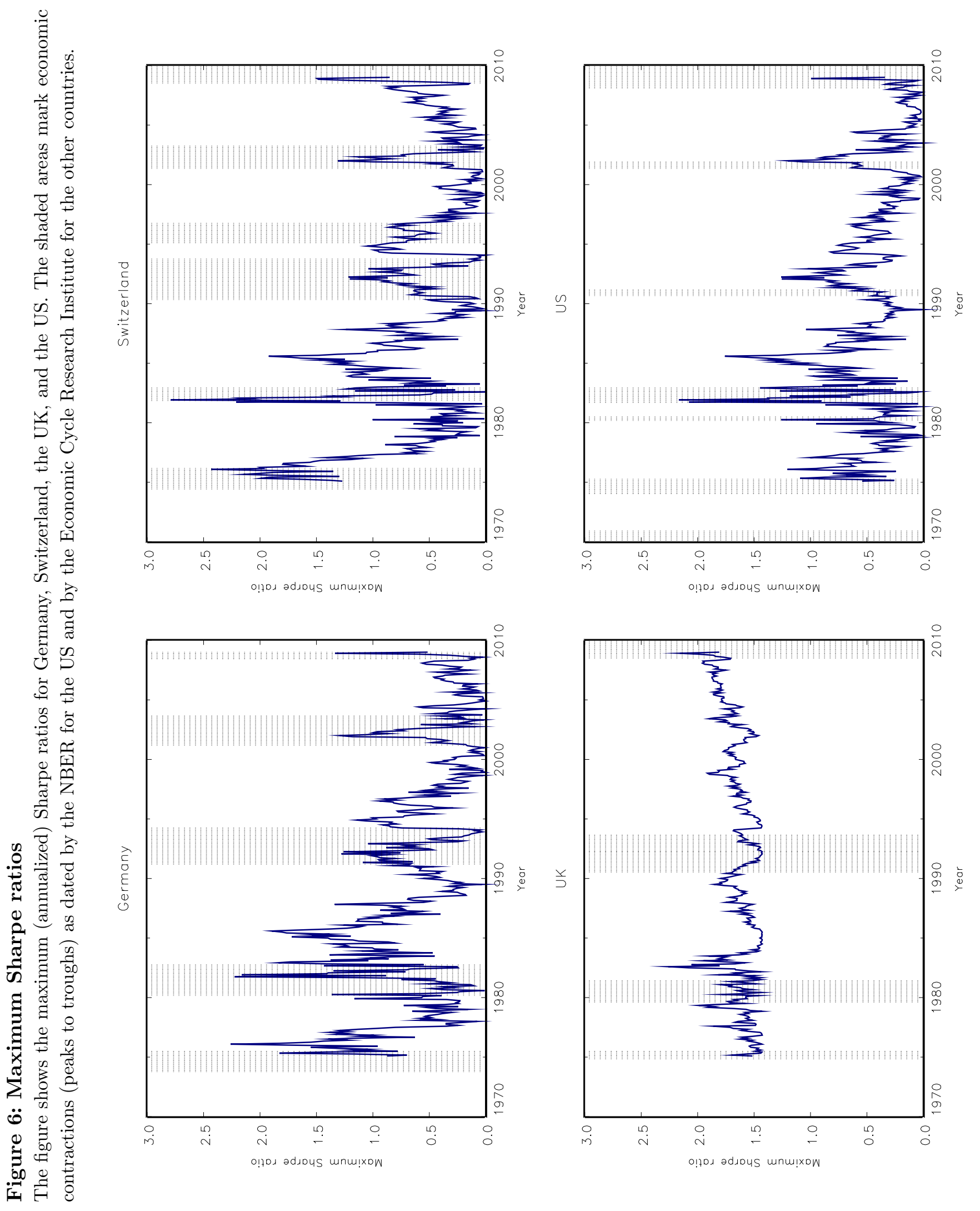




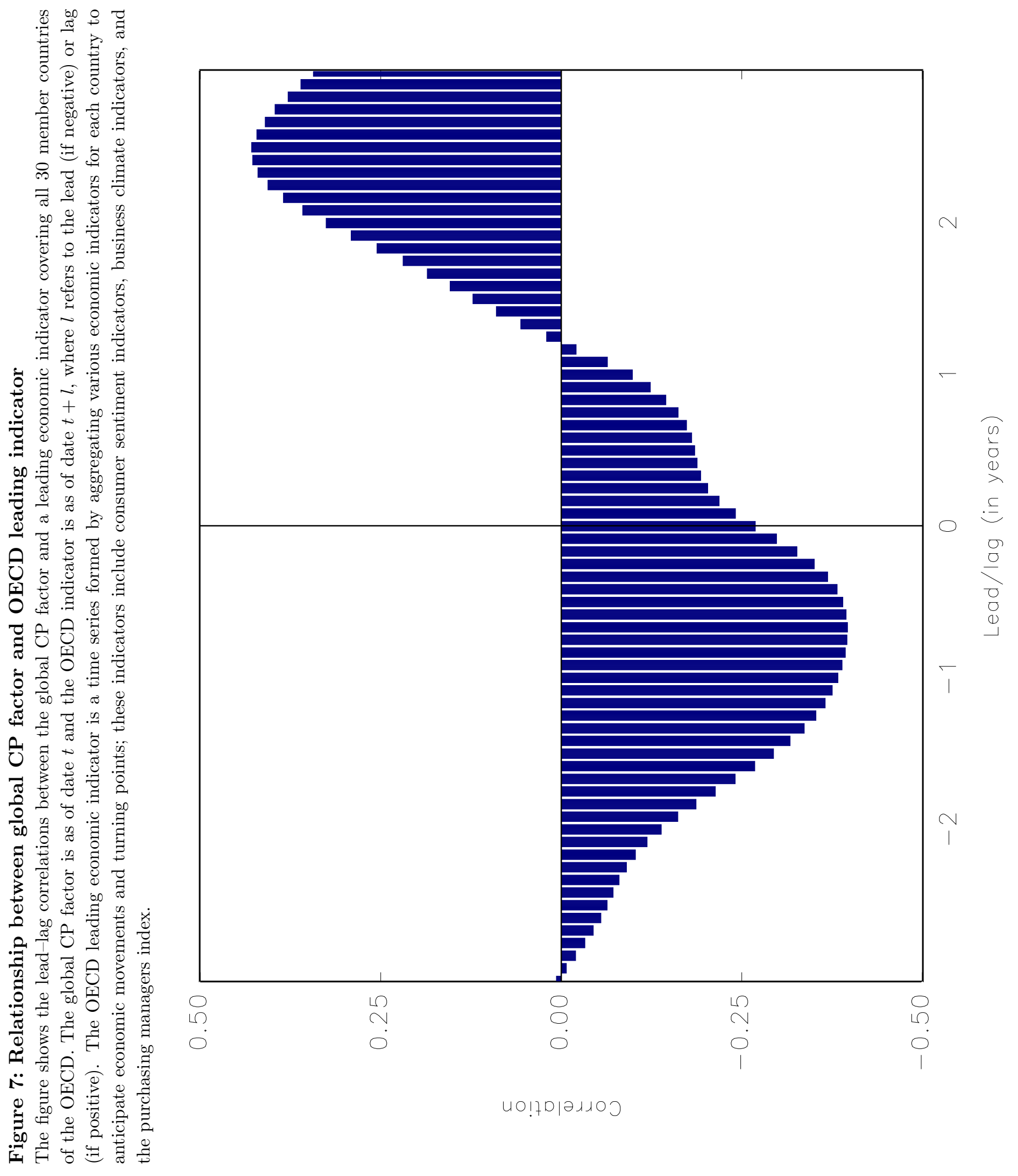




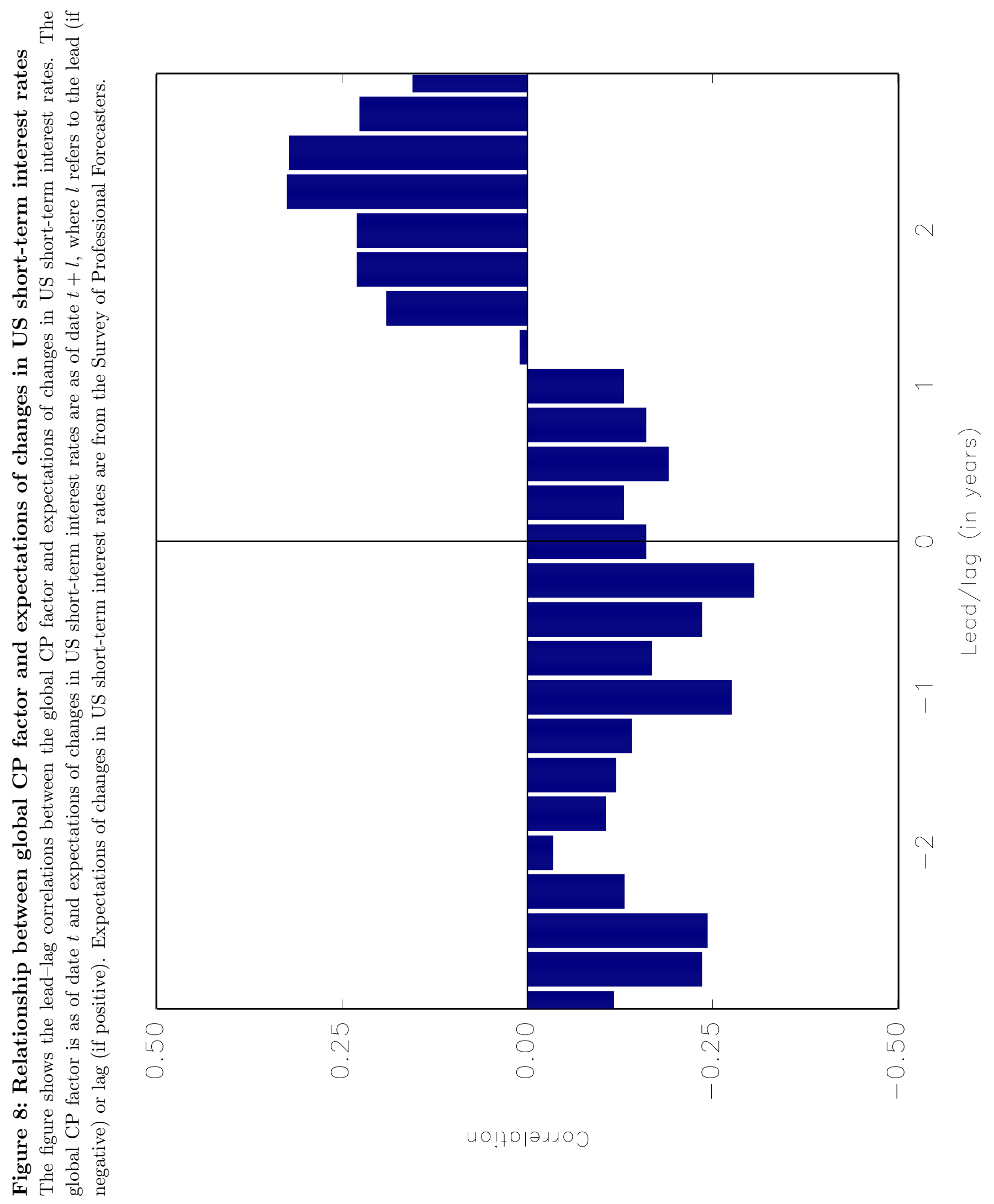

